Article

\title{
Development of a Four-Enzyme Magnetic Nanobiocatalyst for Multi-Step Cascade Reactions
}

\author{
Archontoula Giannakopoulou ${ }^{1}$, Michaela Patila ${ }^{1}$, Konstantinos Spyrou ${ }^{2}$, Nikolaos Chalmpes ${ }^{2}$, \\ Dimitra Zarafeta ${ }^{3}$, Georgios Skretas ${ }^{3}$, Dimitrios Gournis ${ }^{2}$ (1) and Haralambos Stamatis $1, * \mathbb{C}$ \\ 1 Biotechnology Laboratory, Department of Biological Applications and Technologies, University of Ioannina, \\ 45110 Ioannina, Greece; arxontoula.gian@gmail.com (A.G.); michaelapatila@gmail.com (M.P.) \\ 2 Department of Materials Science \& Engineering, University of Ioannina, 45110 Ioannina, Greece; \\ konstantinos.spyrou1@gmail.com (K.S.); chalmpesnikos@gmail.com (N.C.); dgourni@uoi.gr (D.G.) \\ 3 Institute of Biology, Medicinal Chemistry \& Biotechnology, National Hellenic Research Foundation, \\ 11635 Athens, Greece; dimitra.zarafeta@gmail.com (D.Z.); gskretas@eie.gr (G.S.) \\ * Correspondence: hstamati@uoi.gr; Tel.: +30-26-5100-7116
}

Received: 4 November 2019; Accepted: 22 November 2019; Published: 27 November 2019

\begin{abstract}
We report the preparation, characterization and application of a novel magnetic four-enzyme nanobiocatalyst prepared by the simultaneous covalent co-immobilization of cellulase (CelDZ1), $\beta$-glucosidase (bgl), glucose oxidase (GOx) and horseradish peroxidase (HRP) onto the surface of amino-functionalized magnetic nanoparticles (MNPs). This nanobiocatalyst was characterized by various spectroscopic techniques. The co-immobilization process yielded maximum recovered enzymatic activity (CelDZ1: 42\%, bgl: 66\%, GOx: $94 \%$ and HRP: $78 \%$ ) at a 10\% $v / v$ cross-linker concentration, after $2 \mathrm{~h}$ incubation time and at 1:1 mass ratio of MNPs to total enzyme content. The immobilization process leads to an increase of $K_{m}$ and a decrease of $V_{\max }$ values of co-immobilized enzymes. The thermal stability studies of the co-immobilized enzymes indicated up to 2 -fold increase in half-life time constants and up to 1.5-fold increase in their deactivation energies compared to the native enzymes. The enhanced thermodynamic parameters of the four-enzyme co-immobilized MNPs also suggested increment in their thermal stability. Furthermore, the co-immobilized enzymes retained a significant part of their activity (up to $50 \%$ ) after 5 reaction cycles at $50{ }^{\circ} \mathrm{C}$ and remained active even after $24 \mathrm{~d}$ of incubation at $5{ }^{\circ} \mathrm{C}$. The nanobiocatalyst was successfully applied in a four-step cascade reaction involving the hydrolysis of cellulose.
\end{abstract}

Keywords: nanobiocatalysis; cascade reactions; multi-enzyme nanoparticles; co-immobilization; cellulase; $\beta$-glucosidase; glucose oxidase; horseradish peroxidase; cellulose hydrolysis

\section{Introduction}

Enzymes, widely employed as green catalysts, are versatile protein biomolecules with high stereo- and regio-selectivity that catalyze numerous biochemical reactions of industrial importance. They are preferred over conventional chemical catalysts due to their high turnover rates under mild reaction conditions and the reduction of by-product formation [1]. Therefore, biocatalysis that relies on enzymatic processes has rapidly gained considerable attention as a less toxic and eco-friendly approach. Its tremendous applications include an expanded range of fields, such as the production of biofuels, pharmaceuticals, foods, textiles and cosmetics [2]. However, enzymes in their free form are typically unstable and may undergo denaturation under harsh reaction conditions, settling challenges in their handling and separation. Moreover, most of the desired chemical reactions are composed of many steps and cannot be effectively catalyzed by a single enzyme. Thus, several enzymes working together in multi-step reactions or cascade processes are desired [3]. However, the development of robust 
multi-enzyme biocatalysts that exhibit high operational stability towards organic solvents or extreme $\mathrm{pH}$ and temperature conditions, along with facile recoverability and reusability, remains challenging.

Multi-enzymatic cascade reactions, that is, the integration of several biocatalytic transformations proceeding in a concurrent fashion, offer a wide range of opportunities and new paths to the synthesis of high-added value products. Such systems could improve biocatalytic processes by saving time and reducing waste, while being self-sufficient in terms of co-factor requirements [4-6]. Moreover, multi-enzyme cascade biocatalytic systems could offer the possibility of mimicking metabolic pathways of living cells by cascading multi-enzyme reactions or even the development of artificial metabolic pathways that do not appear in nature [7]. Finally, as there is an increasing urgency for greener and more sustainable alternative ways of producing chemicals and bioproducts, cascade reactions can be a highly promising approach in this direction by eliminating short conventional step-by-step synthesis [8,9].

Enzyme immobilization, namely the confinement of an enzyme on an insoluble matrix, is considered a promising technique that can address recoverability and reusability issues and broaden the industrial implementation of enzymes [10]. Moreover, the rapid growth of nanotechnology over the last few decades has provided various nanomaterials, which have been utilized as potential nanocarriers both in single and multi-enzyme immobilization [11-13]. Nanoparticles (NPs) exhibit numerous advantages, such as high surface area-to-volume ratio and nanoscale size, that provides them with excellent electronic, chemical, optical and physical properties as well as mechanical stability $[14,15]$. Among the various available nanomaterials, magnetic nanoparticles (MNPs) hold a prominent position due to their distinct characteristics [16]. These nanomatrices offer the great advantage of easy separation from the reaction mixture just by the application of an external magnetic field, thus overcoming recoverability and reusability issues so that the overall handling process is notably facilitated. So far, several enzymes have been successfully immobilized onto various types of magnetic nanoparticles [17-19] indicating favorable activity and stability.

Inspired by the cascade processes in nature, scientists have recently developed effective strategies in order to artificially co-localize diverse enzymes on nanocarriers for the development of nanobiocatalytic systems [20,21]. Multi-enzyme immobilization places several free enzymes in proximity, thus enabling the substrate channeling effect that can remarkably reduce diffusion losses and accelerate the overall cascade reaction rate [22-24]. So far, the successful simultaneous covalent co-immobilization of various classes of enzymes, mainly hydrolases and oxidoreductases, on magnetic nanoparticles for the catalysis of cascade reactions of biotechnological interest has been reported. These reactions involve, for example, the synergistic hydrolysis of natural biopolymers, such as starch into high-added value products or the development of biosensors for biomedical applications $[17,18,25,26]$. To date, the reported multi-enzyme nanobiocatalytic systems reported consist of at least three enzymes.

In this study, we report, to the best of our knowledge, the first example of simultaneous covalent co-immobilization of four enzymes, a cellulase (CelDZ1), a $\beta$-glucosidase (bgl), a glucose oxidase (GOx) and horseradish peroxidase (HRP) (Table 1), onto the surface of amino-functionalized magnetic nanoparticles (MNPs) for the hydrolysis of cellulose through a four-step cascade reaction. Cellulose, an abundant biopolymer, consists of several glucose units connected through $\beta-1,4$-glucosidic bonds. Hence, its breakdown can lead to glucose, oligosaccharides or other intermediates of significant importance, such as gluconic acid, offering new possibilities in its industrial exploitation. Under optimal conditions, CelDZ1 hydrolyzes soluble cellulose (CMC) into simpler sugar molecules, such as cellobiose, which can be subsequently hydrolyzed by bgl into glucose. The produced glucose serves as a substrate for GOx that oxidizes it to gluconic acid and $\mathrm{H}_{2} \mathrm{O}_{2}$. Finally, the last step of the cascade process involves the HRP-mediated reduction of $\mathrm{H}_{2} \mathrm{O}_{2}$ to $\mathrm{H}_{2} \mathrm{O}$ in the presence of an electron donor. So, the prepared magnetic nanobiocatalytic system herein could be established as a model system for the study of cascade reactions of biotechnological interest in terms of kinetic behavior or thermal stability. Maghemite iron nanoparticles $\left(\gamma-\mathrm{Fe}_{2} \mathrm{O}_{3}\right)$ functionalized with (3-Aminopropyl) triethoxysilane (Aptes) were chosen as the carrier for the co-immobilization of the four enzymes of 
interest. For the preparation of the magnetic nanobiocatalyst several parameters were optimized, including the glutaraldehyde cross-linker concentration, the incubation time and the mass ratio of magnetic nanoparticles to total enzyme content. The resultant nanobiocatalyst was characterized by various spectroscopic methods such as Fourier transform infrared spectroscopy (FTIR), X-ray diffraction (XRD), X-ray photoelectron spectroscopy (XPS) and atomic force microscopy (AFM). Furthermore, we evaluated the kinetic parameters $\left(\mathrm{V}_{\max }\right.$ and $\left.\mathrm{K}_{\mathrm{m}}\right)$ and the thermal stability in terms of deactivation rate constants $\left(k_{d}\right)$, half-life time constants $\left(t_{1 / 2}\right)$ and deactivation energy $\left(E_{d}\right)$. Moreover, we presented a comprehensive analysis of the thermodynamic profile of the co-immobilized system. Additionally, we examined the reusability of the four-enzyme magnetic nanobiocatalyst for five consecutive reaction cycles and its storage stability for $24 \mathrm{~d}$. Finally, the magnetic nanobiocatalyst was successfully applied to a four-step cascade reaction involving the hydrolysis of cellulose and the conversion of glucose to gluconic acid.

Table 1. Molecular mass (MM) and isoelectric point (pI) of the four enzymes employed for co-immobilization onto the surface of amino-functionalized magnetic nanoparticles.

\begin{tabular}{ccc}
\hline Enzyme & M.M. (kDa) & pI \\
\hline Cellulase, CelDZ1, from a & 42 & 5.7 \\
Thermoanaerobacterium hot spring isolate [27] & 53.7 & 6.0 \\
B-Glucosidase from Thermotoga maritima & 160 & 4.2 \\
Glucose oxidase from Aspergillus niger & 40 & 7.2 \\
\hline Horseradish peroxidase &
\end{tabular}

\section{Results and Discussion}

\subsection{Synthesis and Characterization of the Magnetic Nanoparticles}

For the preparation of the organophilic iron nanoparticles, a thermolysis method was used based on the thermolytic decomposition of an iron chloride precursor, using oleylamine both as solvent and capping agent. A first indication about the structure of the iron nanoparticles was gained from the XRD pattern (Supplementary Materials Figure S1). The peaks appearing in the range of $20^{\circ}$ and $80^{\circ}$ can be assigned to the crystallographic Miller planes (220), (311), (400), (422), (511), (440) indicative of $\gamma$ - $\mathrm{Fe}_{2} \mathrm{O}_{3}$ phase [19]. Moreover, in order to confirm the size of the magnetic nanoparticles, AFM height images of the $\gamma-\mathrm{Fe}_{2} \mathrm{O}_{3}$ nanoparticles deposited on a Si-wafer were collected (the micrographs are shown in Figure S2, Supplementary Materials). Relatively isolated and uniform $\gamma-\mathrm{Fe}_{2} \mathrm{O}_{3}$ nanoparticles without aggregation can be observed. The average heights of the pristine nanoparticles range in the areas of $7-10 \mathrm{~nm}$, as derived from the topographical height profile (section analysis).

\subsection{Preparation of the Magnetic Four-Enzyme Nanobiocatalyst}

CelDZ1, bgl, GOx and HRP (at a typical mass ratio of 1:1:1:3) were covalently attached onto the surface of amino-functionalized magnetic nanoparticles employing glutaraldehyde to prevent leaching of enzymes during the cascade reaction. The mass ratio for the co-immobilization of the four enzymes was chosen based on preliminary results (data not shown), as well as on the immobilization yield that each enzyme exhibited when immobilized individually (Table S1). Specifically, we varied the mass ratio of CelDZ1, bgl, GOx and HRP from 1:1:1:1 to 1:1:1:3, respectively. It was indicated that the use of excess HRP concentration during the immobilization process, enhanced the final step of the studied cascade process, a result that is in accordance with other studies that reported that the increase in the initial amount of HRP is essential in the development of robust bi-enzymatic systems comprising of GOx and HRP [28,29]. Glutaraldehyde, acting as a bifunctional cross-linker, reacts with the amino groups of both the enzymes and the MNPs, directly affecting enzyme loading, activity recovery and operational stability of the prepared nanobiocatalyst [30]. Hence, the effect of cross-linker concentration on the activity recovery of the enzymes was investigated (at $2 \mathrm{~h}$ incubation 
time and molar ratio 1:1 w/w MNPs-to-enzyme mass ratio mass ratio) and the results are presented in Figure 1a. As it can be seen, enzyme activity recovery strongly depends on the glutaraldehyde concentration and a maximum activity recovery for bgl, GOx and $\mathrm{HRP}(58 \%, 73 \%$ and $30 \%$ respectively) was observed at $10 \% v / v$ cross-linker concentration, while for CelDZ1 (30\%) it was observed at $15 \%$ $v / v$, implying that the varieties of the enzymes can directly affect their recovery activities. At higher or lower glutaraldehyde concentrations, the enzymatic activities were significantly reduced for all the enzymes. Lower cross-linker concentrations may not be sufficient to bind all enzymes on MNPs, while at higher concentrations, abundant covalent linkages might occur between all the molecules interfering with the co-immobilization procedure and thus leading to a loss in enzymes' activity. These results are in agreement with previous studies $[16,17,25]$ that also report that the activity recoveries for all the enzymes participating in multi-enzyme nanobiocatalytic systems tend to increase with increasing glutaraldehyde concentration. However, after reaching a maximum value, the activities begin to decline with increasing glutaraldehyde concentration.

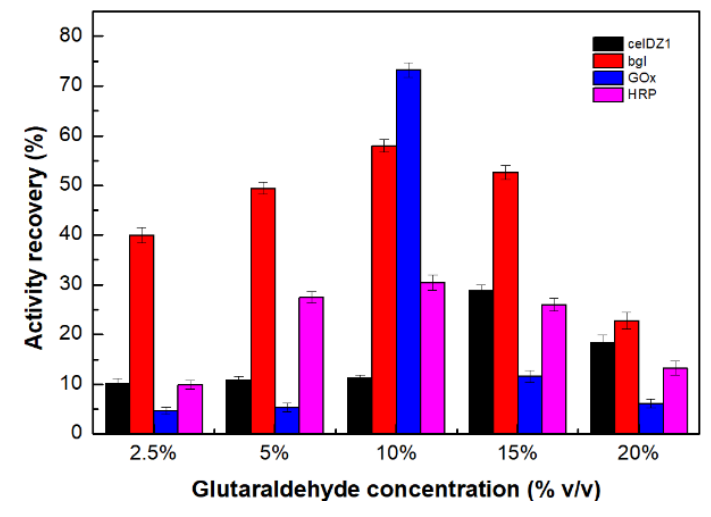

(a)

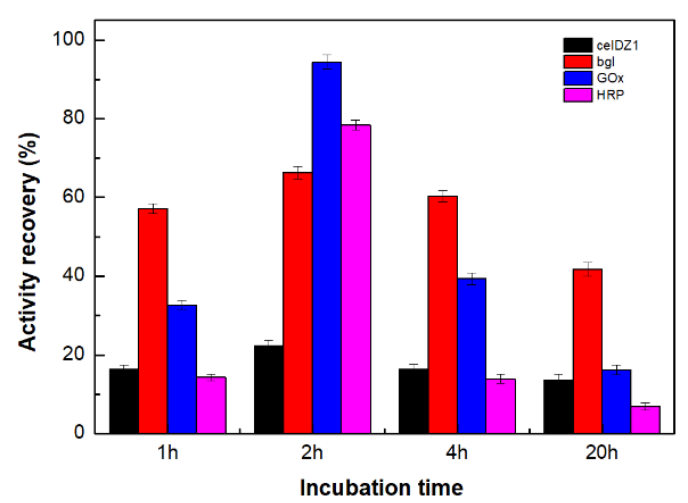

(b)

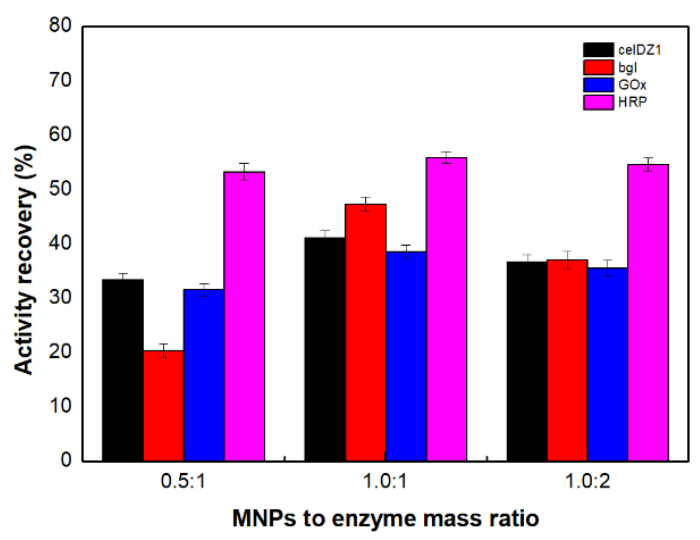

(c)

Figure 1. Effect of immobilization parameters on the activity recovery of the enzymes as a function of: (a) cross-linker concentration, (b) immobilizing time and (c) magnetic nanoparticles-to-enzymes mass ratio.

Incubation time is another critical parameter that affects the activity recovery of the enzymes during the co-immobilization process. Figure $1 \mathrm{~b}$, shows that the activity recovery of all enzymes increased with increasing incubation time (at 10\% $v / v$ glutaraldehyde concentration and at 1:1 w/w MNPs-to-enzyme mass ratio mass ratio) demonstrating a maximum activity recovery after $2 \mathrm{~h}$ of incubation (CelDZ1: 22\%, bgl: 66\%, GOx: 94\% and HRP: 78\%). Lower immobilizing time might not be enough for all the enzymes to be bound onto MNPs. However, at extended incubation times, a decline in activity recoveries was observed. This can be possibly attributed to the fact that glutaraldehyde 
might have caused rigidification of enzymes in the co-immobilized form, restricting their flexibility and, thus, reducing their activities [17].

Moreover, in order to optimize the mass ratio of magnetic nanoparticles-to-enzyme content, the activity recovery of all the enzymes was determined by varying the mass ratios of the nanocarrier-to-enzyme cocktail from 0.5:1 to 2:1 $(w / w)$. The glutaraldehyde concentration was maintained at $10 \% v / v$ and the incubation time was $2 \mathrm{~h}$. As shown in Figure 1c, lower activities were observed at the lowest mass ratio of $0.5: 1(w / w)$, probably due to the insufficient available surface area of the nanocarrier to load all the enzymes, resulting in decreased activity recovery. Enzymes reached their maximum activity recoveries at a mass ratio of 1:1 w/w (CelDZ1: $41 \%$, bgl: $47 \%$, GOx: $38 \%$ and HRP: $56 \%$ ), while a further increase in the MNPs-to-enzyme mass ratio leads to lower binding of the enzymes onto the nanocarrier probably due to enhanced immobilization on the surface, consequently leading to steric hindrance amongst the enzymes [26]. Muley et al., who have previously studied the co-immobilization of cellulase, pectinase and xylanase onto amino-functionalized magnetic nanoparticles, also demonstrated that the ratio of MNPs to enzyme activity recoveries increased with increasing ratio up to a maximum value and then declined [18].

Hence, based on the results presented above, the four-enzyme magnetic nanobiocatalyst was prepared by cross-linking enzymes onto MNPs employing glutaraldehyde as cross-linking agent at $10 \% v / v$ concentration, incubation time of $2 \mathrm{~h}$ and at 1:1 mass ratio of MNPs-to-enzyme content. These conditions resulted in maximum activity recoveries of CelDZ1, bgl, GOx and HRP (42\%, 66\%, 94\% and $78 \%$ respectively).

\subsection{Characterization of the Four-Enzyme Magnetic Nanobiocatalyst}

\subsubsection{Fourier Transform Infrared Spectroscopy (FTIR)}

The FTIR spectra of the prepared magnetic nanoparticles, in the form of amino-functionalized magnetic nanoparticles and four-enzyme magnetic nanoparticles (Figure 2), were recorded in order to confirm the functionalization of MNPs with Aptes and the successful anchoring of the enzymes. A characteristic peak of the prepared $\gamma$-Fe-Aptes, observed at $568 \mathrm{~cm}^{-1}$ corresponds to the Fe-O stretching vibrations [25]. The confirmation of the silica network on NPs after functionalization with Aptes, can be attributed to the distinct peaks at 1040 and $1120 \mathrm{~cm}^{-1}$ corresponding to the Si-O-Si and Si-O-H groups, respectively [16]. Moreover, the distinct peaks at 1393 and $1630 \mathrm{~cm}^{-1}$ corresponding to the Aptes $\mathrm{C}-\mathrm{H}$ scissoring vibration and $\mathrm{N}-\mathrm{H}$ stretching vibration, respectively, also confirm the functionalization of the magnetic nanoparticles with Aptes. The peak at $2931 \mathrm{~cm}^{-1}$ corresponds to the $-\left(\mathrm{CH}_{2}\right)_{\mathrm{n}}$-group and arises from the Aptes C-H stretching. Finally, the absorption peak at $3400 \mathrm{~cm}^{-1}$ corresponds to the $\mathrm{O}-\mathrm{H}$ stretching vibration [31-33].

The FTIR spectrum of the prepared $\gamma$-Fe-Aptes-4-enzyme is additionally characterized by a sharp peak at $1540 \mathrm{~cm}^{-1}$ attributed to the $\mathrm{C}-\mathrm{N}$ stretching and $\mathrm{N}-\mathrm{H}$ bending vibrations corresponding to the Amide II band. Furthermore, the sharp peak at $1653 \mathrm{~cm}^{-1}$ which is attributed to $C=0$ stretching vibrations of the enzymes and corresponds to Amide I band, verifies the anchoring of the four-enzyme mixture on the MNPs. The successful binding of the enzymes can be also proved by the distinct peak at $3280 \mathrm{~cm}^{-1}$ corresponding to the $\mathrm{N}-\mathrm{H}$ asymmetric stretching of the amine $\mathrm{H}$-bonds or the $\mathrm{O}-\mathrm{H}$ vibrations [17]. 


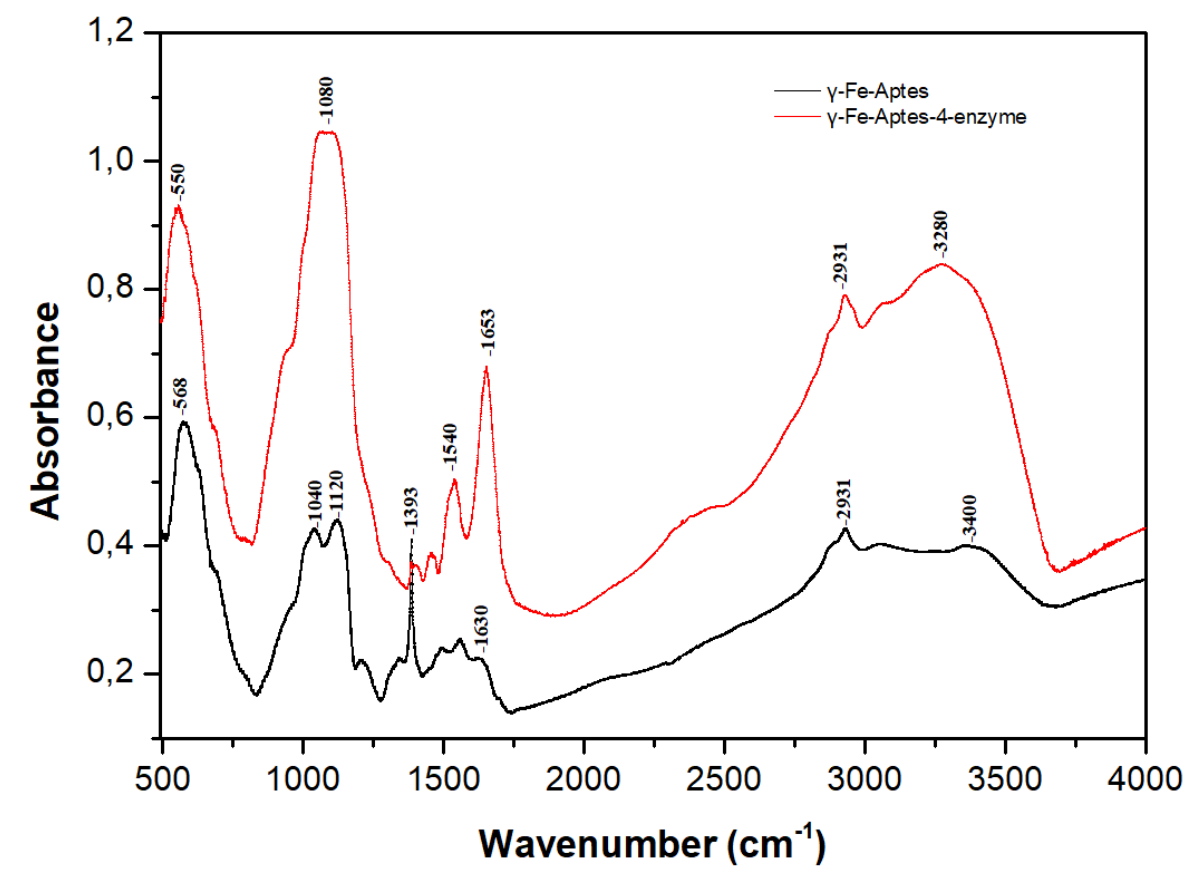

Figure 2. Fourier transform infrared (FTIR) spectra of amino functionalized magnetic nanoparticles (black) and four-enzyme co-immobilized nanoparticles (red), showing their distinct peaks.

\subsubsection{X-ray Photoelectron Spectroscopy (XPS)}

In order to get deeper information concerning the co-immobilization of CelDZ1, bgl, GOx and HRP onto the surface of the amino functionalized magnetic nanoparticles, as well the type of interactions of these specific enzymes we employed XPS measurements. The Fe2p photoelectron spectrum presented in Figure 3a reveals the existence of $\gamma-\mathrm{Fe}_{2} \mathrm{O}_{3}$ nanoparticles, which is in good agreement with the XRD patterns (Supplementary Materials, Figure S1). After the immobilization of the enzymes we do not observe any significant shift of the Fe2p spectrum which is an evidence of no strong interaction of the enzymes with the core of the Fe nanoparticles (Figure 3c). From the $\mathrm{C}$ 1s photoelectron spectra we collect data from the functionalization of $\mathrm{Fe}_{2} \mathrm{O}_{3}$ nanoparticles with Aptes (Figure 3b), as well information after the 4-enzyme co-immobilization (Figure 3d). C1s of the amino-functionalized magnetic nanoparticles reveals the different bonds of carbon such as C-Si from the successful interaction of Aptes, the $\mathrm{C}-\mathrm{C}$ and $\mathrm{C}-\mathrm{H}$ bonds from the presence of Aptes, as well the C-O and C-N bonds at $286.0 \mathrm{eV}$. We also observe at $287.3 \mathrm{eV}$ bonds of carbon derived from epoxy or carbonyl groups and carboxyl groups at $289.3 \mathrm{eV}$ probably due to the functional carbon groups of the magnetic nanoparticles (Figure $3 \mathrm{~b}$ ). After the co-immobilization procedure on the surface of the amino-functionalized magnetic nanoparticles, the $\mathrm{C} 1 \mathrm{~s}$ spectra changes and this is because of the existence of the four different enzymes interacting with the functionalized magnetic nanoparticles as Figure $3 \mathrm{~d}$ reveals. The successful covalent co-immobilization is demonstrated by the existence of an amide peak at $287.9 \mathrm{eV}$ representing $16.9 \%$ of the whole carbon amount [34]. Finally, from the N1s photoelectron spectrum (Figure 3e) of the 4-enzyme magnetic nanobiocatalyst we receive three photoelectron peaks. The first one centered at $398.0 \mathrm{eV}$ is due to pyridinic $\mathrm{N}$ exist in the glucose oxidase's cofactor (flavin adenine dinucleotide, FAD) formation and representing $18.2 \%$ of the nitrogen amount. The second peak is due to $\mathrm{NH}$ bonds $(36.2 \%)$, while the peak at $401.0 \mathrm{eV}$ is attributed to the amide formation from the covalent functionalization as well from the amide groups of all the participating enzymes [34]. 


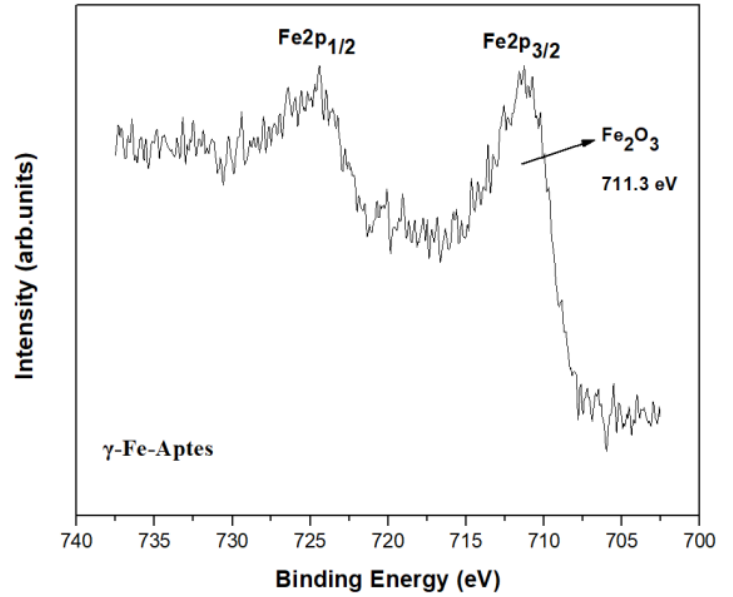

(a)

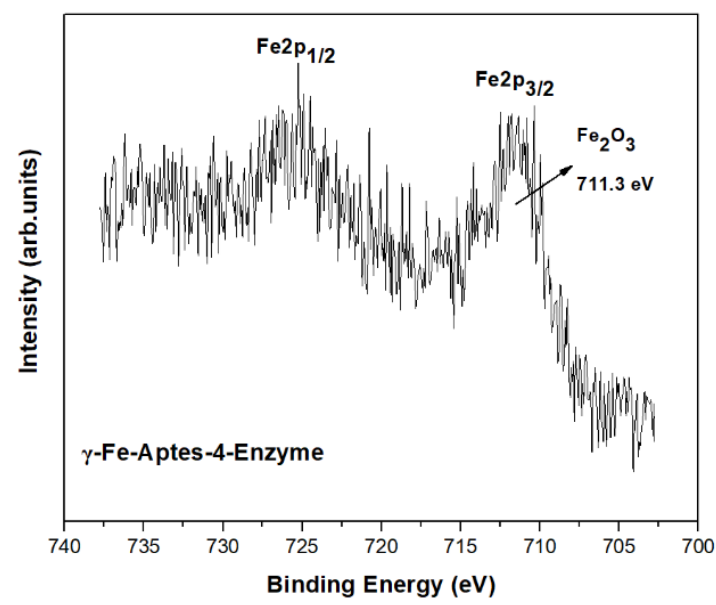

(c)

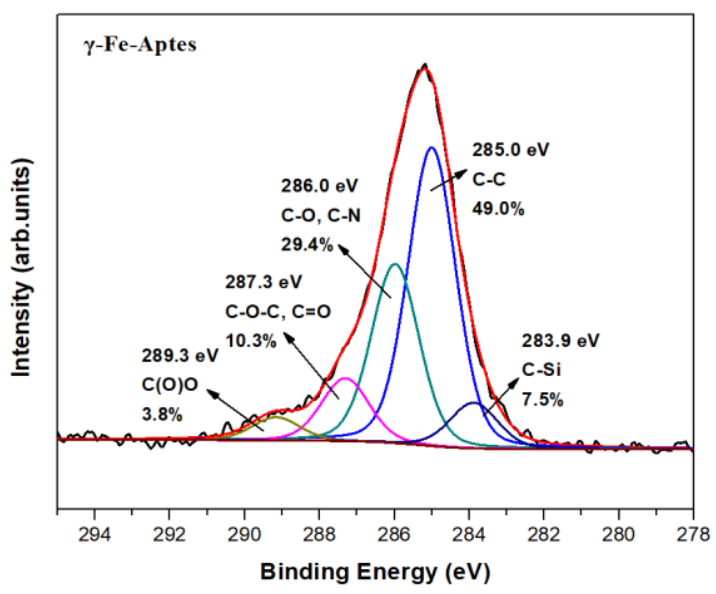

(b)

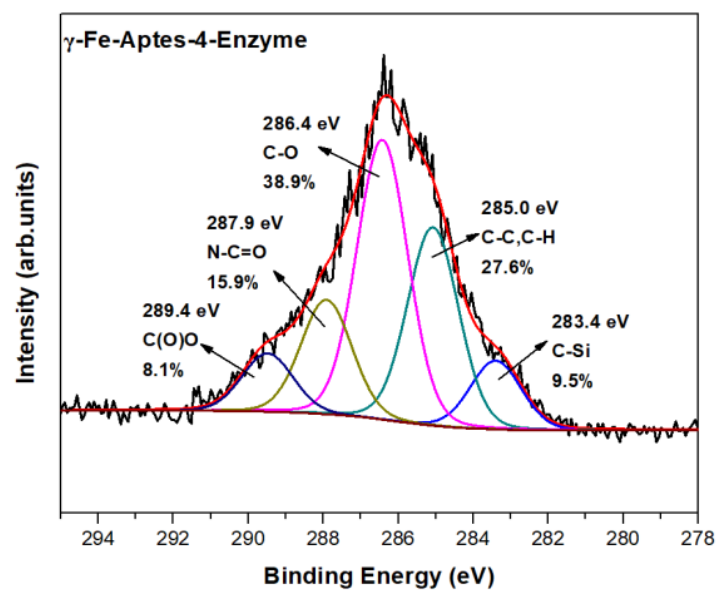

(d)

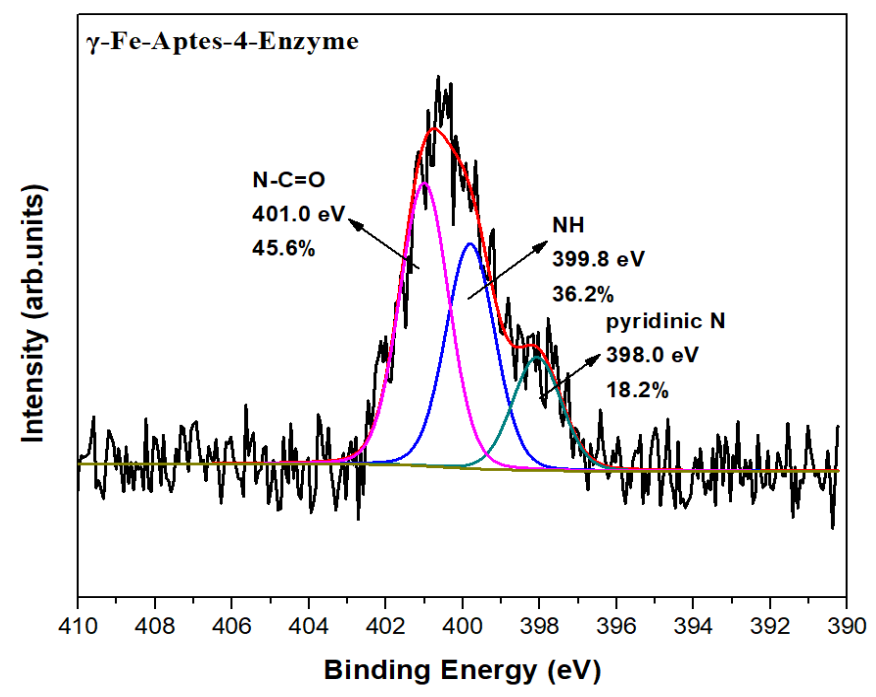

(e)

Figure 3. (a) Fe2p photoelectron spectra of amino functionalized magnetic nanoparticles (MNPs), (b) C1s photoelectron spectra of amino functionalized MNPs, (c) Fe2p photoelectron spectra of the 4-enzyme magnetic nanobiocatalyst, (d) C1s photoelectron spectra of the 4-enzyme magnetic nanobiocatalyst, and (e) N1s photoelectron spectra of the 4-enzyme magnetic nanobiocatalyst. 


\subsection{Thermal Stability Studies of Magnetic Four-Enzyme Nanobiocatalyst}

In order to investigate the thermal stability of the free form (FF) and co-immobilized form (CIF) of the enzymes CelDZ1, GOx and HRP, we incubated each form (in absence of respective substrate) in sodium phosphate buffer in the range of 30 to $60^{\circ} \mathrm{C}$. For bgl, it was chosen a temperature range from 70 to $90^{\circ} \mathrm{C}$ as it is considered a highly thermostable enzyme [35] and no significant decline in residual activity was observed after $2 \mathrm{~h}$ of incubation up to $70^{\circ} \mathrm{C}$. Plots of residual activity [expressed as $\ln \left(\mathrm{A} / \mathrm{A}_{\mathrm{o}}\right)$ ] against time were plotted as illustrated in Figure 4 in order to determine the deactivation rate constants $\left(k_{d}\right)$ as well as the half-life time $\left(t_{1 / 2}\right)$ at all studied temperatures for each enzyme, both in free and co-immobilized form. The values for the half-life time $\left(t_{1 / 2}\right)$ at $50{ }^{\circ} \mathrm{C}$ for CelDZ1, GOx and HRP and at $70{ }^{\circ} \mathrm{C}$ for bgl are summarized in Table 2 (the values for the half-life time at all the other temperatures are more comprehensively represented on Tables S2-S4, Supplementary Materials). Results indicate that the thermal inactivation kinetics of all the enzymes, both in free and co-immobilized form, presented gradual reduction in activity with increasing temperature at an extended incubation period, showing linearity and thus suggesting that the inactivation rates follow first-order kinetics [26].

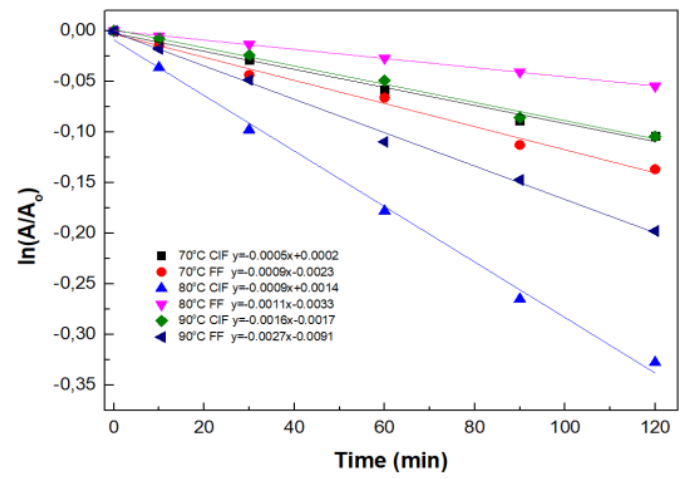

(a)

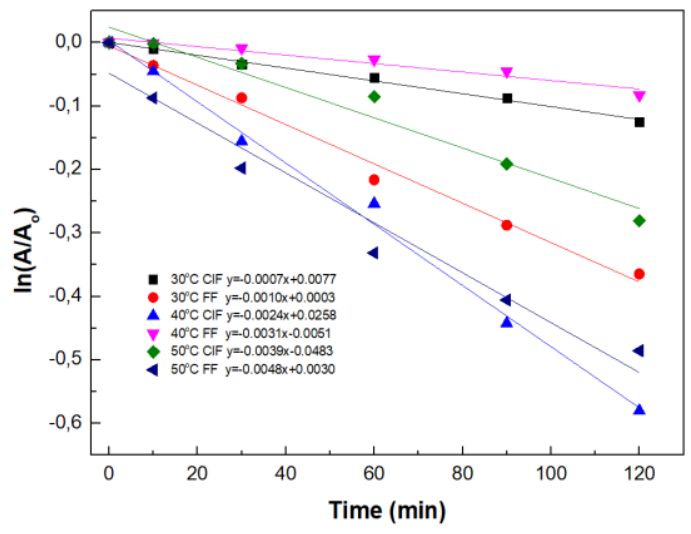

(c)

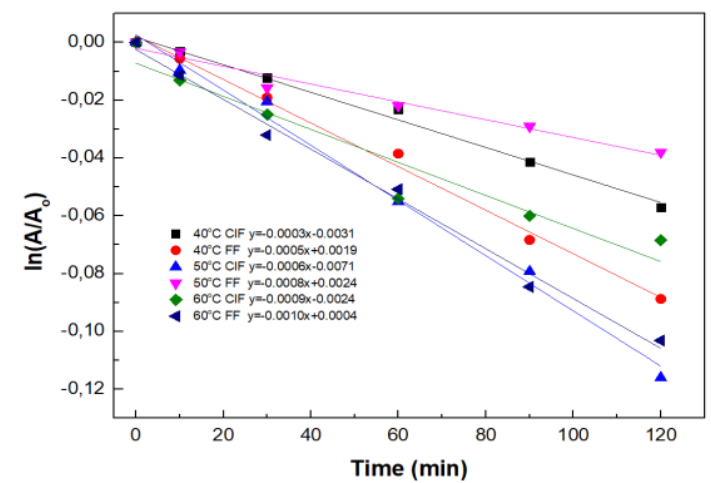

(b)

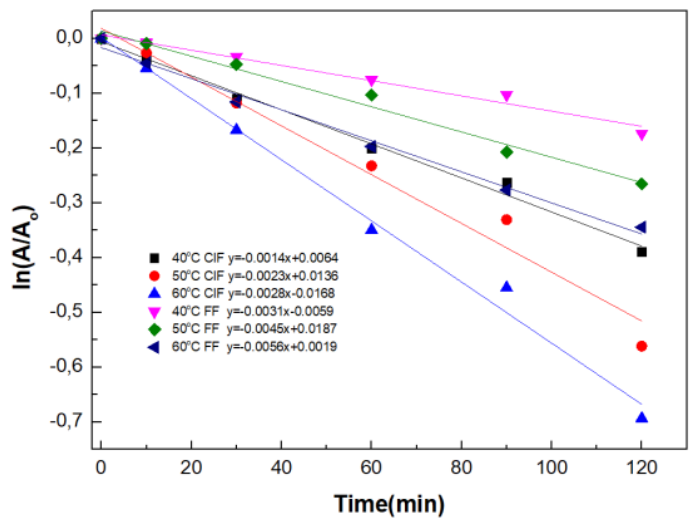

(d)

Figure 4. Thermal inactivation kinetics of free and co-immobilized (a) bgl, (b) GOx, (c) HRP and (d) CelDZ1.

The thermal inactivation constant $\left(\mathrm{k}_{\mathrm{d}}\right)$ of the magnetic nanobiocatalyst in co-immobilized form, as obtained from the semi-log plots of residual activity against time, was significantly lower than that of free form at all studied temperatures. On the other hand, the $t_{1 / 2}$ values (on average, for CelDZ1: 2.0-fold, for bgl: 1.8-fold, for GOx: 1.3-fold and for HRP: 1.2-fold) was undoubtedly higher in the co-immobilized form when compared to the free form of all the enzymes at all temperatures, indicating enhanced thermal stability. The improved thermal stability after co-immobilization can be attributed to 
the strong covalent bonds between the amino groups present both on the surface of MNPs and enzymes via cross-linking with glutaraldehyde that protects the catalytic conformations of enzymes, conserving and stabilizing the structural conformation of the co-immobilized complex $[18,36]$. Increased $t_{1 / 2}$ values have been also observed for cellulases after co-immobilization on Au-doped magnetic silica nanoparticles [25], as well as for cellulase, pectinase and xylanase after co-immobilization on magnetic nanoparticles [18].

Table 2. Half- life times $\left(\mathrm{t}_{1 / 2}\right)\left(\right.$ at $50^{\circ} \mathrm{C}$ for CelDZ1, GOx and horseradish peroxidase (HRP) and at 70

${ }^{\circ} \mathrm{C}$ for bgl) and deactivation energies $\left(\mathrm{E}_{\mathrm{d}}\right)$ for each enzyme both in free and co-immobilized form.

\begin{tabular}{ccc}
\hline Enzyme & $\mathbf{t}_{\mathbf{1 / 2}} \mathbf{( h )}$ & $\left.\mathbf{E}_{\mathbf{d}} \mathbf{( k J} / \mathbf{m o l}\right)$ \\
\hline Free form of CelDZ1 & 2.5 & 25.7 \\
Co-immobilized form of CelDZ1 & 5.0 & 30.1 \\
Free form of bgl & 12.8 & 57.5 \\
Co-immobilized form of bgl & 23.1 & 60.2 \\
Free form of GOx & 14.4 & 30.1 \\
Co-immobilized form of GOx & 19.2 & 47.7 \\
Free form of HRP & 2.4 & 64.1 \\
Co-immobilized form of HRP & 2.9 & 70.1 \\
\hline
\end{tabular}

Deactivation energy $\left(E_{d}\right)$, another crucial parameter in determining the thermal stability of an enzyme, refers to the energy required to dissociate its tertiary catalytic conformation [17]. It can be calculated from the slope of the Arrhenius plot (Supplementary Materials, Figures S3-S6) and it is summarized in Table 2. As can be observed, at all studied temperatures, the difference in values of deactivation energies between the free and co-immobilized form of CelDZ1, bgl, GOx and HRP was estimated at $4.4 \mathrm{~kJ} / \mathrm{mol}, 2.7 \mathrm{~kJ} / \mathrm{mol}, 17.6 \mathrm{~kJ} / \mathrm{mol}$ and $6.0 \mathrm{~kJ} / \mathrm{mol}$, respectively. Higher deactivation energy accounts for a highly thermostable catalyst. These results suggest the preparation of a stable nanobiocatalyst that was less sensitive to temperature changes than native enzymes, thus requiring higher energies to dissociate its structural conformation [37]. Therefore, both the support chosen for the co-immobilization as well as the co-immobilization protocol seem to significantly improve the thermal stability of each enzyme participating in the magnetic complex. Sojitra et al., who reported the simultaneous covalent co-immobilization of $\alpha$-amylase, pectinase and cellulase on magnetic nanoparticles also demonstrated a significant increase in the difference of deactivation energy between free and co-immobilized enzymes [17], clearly indicating the nanobiocatalyst's enhanced thermal stability against denaturation at high temperatures after co-immobilization.

\subsection{Determination of Thermodynamic Parameters}

The assessment of the thermodynamic parameters was based on the combination of deactivation energy $\left(E_{d}\right)$ and Eyring's transition state theory [17], in order to evaluate the thermodynamic profile of the four-enzyme magnetic nanobiocatalyst. The results for the thermodynamic parameters, enthalpy of activation $\left(\Delta \mathrm{H}^{\circ}\right)$, Gibbs free energy of denaturation $\left(\Delta \mathrm{G}^{\circ}\right)$ and entropy for activation $\left(\Delta \mathrm{S}^{\circ}\right)$, of free and co-immobilized enzymes, are indicatively represented at $50^{\circ} \mathrm{C}$ for CelDZ1, GOx and HRP and at $70{ }^{\circ} \mathrm{C}$ for bgl in Table 3 (a more comprehensive representation of the $\Delta \mathrm{H}^{\circ}, \Delta \mathrm{G}^{\circ}$ and $\Delta \mathrm{S}^{\circ}$ values at all studied temperatures can be found in Tables S5-S7, see Supplementary Materials).

$\Delta \mathrm{H}^{\circ}$, a significant thermodynamic parameter, corresponds to the total amount of energy that is needed for enzyme denaturation. Hence, high and positive values of $\Delta \mathrm{H}^{\circ}$ are associated with enhanced thermostability during the inactivation process. According to our results, in all cases, the $\Delta \mathrm{H}^{\circ}$ values declined steadily with an increase in temperature, revealing that a lower amount of energy was essential to denature enzymes at higher temperatures. Moreover, the $\Delta \mathrm{H}^{\circ}$ values of the co-immobilized complex were significantly higher compared to native enzymes, indicating that co-immobilization results in higher thermostability $[18,38]$. Another thermodynamic parameter, $\Delta \mathrm{G}^{\circ}$, estimates the spontaneity of the thermal inactivation process, thus providing a measure of enzyme's stability. High values of $\Delta \mathrm{G}^{\circ}$ 
reflect the ability of an enzyme to retain its stability against thermal inactivation, while a low value of $\Delta \mathrm{G}^{\circ}$ accounts for a less stable biocatalyst that can easily undergo unfolding. The $\Delta \mathrm{G}^{\circ}$ values of free and co-immobilized form of enzymes increased with elevated temperature. Moreover, the $\Delta G^{\circ}$ values of the four-enzyme magnetic complex were higher than that of the respective free enzymes, revealing that the co-immobilization procedure onto the amino-functionalized magnetic nanoparticles protects enzymes' structure from denaturation. Finally, $\Delta S^{\circ}$, refers to the amount of energy per degree required for the transition from a native state to a denatured one $[39,40]$. The $\Delta S^{\circ}$ values seemed to be slightly affected after co-immobilization when compared with the free form of the enzymes. Similar results concerning the thermodynamic profile of co-immobilized enzymes have been reported by Farrugia et al., who studied the co-immobilization of bgl, GOx and HRP on protein-polymer surfactant self-standing films [41], as well as by Muley et al. who studied a co-immobilized magnetic complex comprising cellulase, pectinase and xylanase [18].

Table 3. Thermodynamic parameters, $\Delta \mathrm{H}^{\circ}, \Delta \mathrm{G}^{\circ}$ and $\Delta \mathrm{S}^{\circ}$ (at $50^{\circ} \mathrm{C}$ for CelDZ1, GOx and HRP and at $70^{\circ} \mathrm{C}$ for bgl) for each enzyme both in free and co-immobilized form.

\begin{tabular}{cccc}
\hline Enzyme & $\boldsymbol{\Delta \mathbf { H } ^ { \circ } \mathbf { ( k J } / \mathbf { m o l } )}$ & $\boldsymbol{\Delta \mathbf { G } ^ { \circ } \mathbf { ( k J } / \mathbf { m o l } )}$ & $\left.\boldsymbol{\Delta} \mathbf{S}^{\circ} \mathbf{( J / m o l} / \mathbf{K}\right)$ \\
\hline Free form of CelDZ1 & 23.00 & 92.45 & -215.01 \\
Co-immobilized form of CelDZ1 & 27.47 & 94.25 & -208.13 \\
Free form of bgl & 54.65 & 102.91 & -140.69 \\
Co-immobilized form of bgl & 57.35 & 104.60 & -137.75 \\
Free form of GOx & 27.42 & 97.07 & -215.63 \\
Co-immobilized form of GOx & 45.02 & 97.85 & -163.56 \\
Free form of HRP & 61.42 & 92.27 & -95.51 \\
Co-immobilized form of HRP & 67.42 & 92.83 & -78.66 \\
\hline
\end{tabular}

\subsection{Kinetic Parameters}

Enzyme kinetic constants $\left(\mathrm{K}_{\mathrm{m}}\right.$ and $\left.\mathrm{V}_{\max }\right)$ of the free, individually immobilized or co-immobilized form of each enzyme were determined by measuring the initial reaction rates at varying respective substrate concentrations. As shown in Table 4, the apparent $K_{m}$ values of either individually or co-immobilized form of enzymes is higher than that of the free enzymes in all the cases that were examined. $K_{m}$ values for CelDZ1 are expressed in terms of mass $\left(\mathrm{mg} \mathrm{mL}^{-1}\right)$ due to the natural heterogeneity of the substrate, while for the other three enzymes, $\mathrm{K}_{\mathrm{m}}$ is expressed in terms of $\mathrm{mM}$. The increase in $\mathrm{K}_{\mathrm{m}}$ values indicates that the affinity of enzymes towards their substrate declines after immobilization on magnetic nanoparticles. This phenomenon could be attributed to conformational changes on the protein molecules after immobilization, that reduce their flexibility, restricting the diffusion of the respective substrates to the active site of the enzymes. These results are in agreement with previously reported studies $[17,18,26,42]$. Further, the apparent $V_{\max }$ values, in all cases, were significantly decreased after immobilization, indicating lower enzymatic reaction rates of the respective substrates. This is probably arising from the reduction of active sites during the immobilization process due to the rigidification of the biocatalyst by the glutaraldehyde cross-linker [17,42]. A similar increase in $\mathrm{K}_{\mathrm{m}}$ values with a significant decrease in $\mathrm{V}_{\max }$ values has been also reported for the co-immobilization of cellulase, pectinase and xylanase on magnetic nanoparticles [18] and for the co-immobilization of glucose oxidase and glucoamylase on a silver nanostructure [42]. 
Table 4. Apparent kinetic constants of free, individually immobilized and co-immobilized form of CelDZ1, bgl, GOx and HRP.

\begin{tabular}{ccc}
\hline Forms & $\mathbf{K}_{\mathbf{m}}$ & $\mathbf{V}_{\mathbf{m a x}}(\mu \mathbf{m o l} / \mathbf{m i n})$ \\
\hline Free CelDZ1 & $6.09 \pm 0.78$ & $1.41 \pm 0.16$ \\
CelDZ1 in co-immobilized form & $6.78 \pm 0.21$ & $0.40 \pm 0.02$ \\
CelDZ1 in individually immobilized form & $8.15 \pm 2.47$ & $1.22 \pm 0.28$ \\
Free bgl & $0.25 \pm 0.01$ & $37.54 \pm 0.56$ \\
bgl in co-immobilized form & $0.36 \pm 0.05$ & $9.46 \pm 0.26$ \\
bgl in individually immobilized form & $0.46 \pm 0.04$ & $2.36 \pm 0.06$ \\
Free GOx & $1.72 \pm 0.11$ & $12.07 \pm 1.38$ \\
GOx in co-immobilized form & $2.76 \pm 0.98$ & $5.30 \pm 0.28$ \\
GOx in individually immobilized form & $11.93 \pm 1.77$ & $3.70 \pm 0.17$ \\
Free HRP & $0.014 \pm 0.001$ & $20.74 \pm 1.05$ \\
HRP in co-immobilized form & $0.017 \pm 0.013$ & $5.45 \pm 0.57$ \\
HRP in individually immobilized form & $0.044 \pm 0.010$ & $3.66 \pm 0.21$ \\
\hline
\end{tabular}

\subsection{Storage Stability Studies}

The storage stability for each of the four enzymes in the co-immobilized magnetic complex was studied for a total of 24 days during storage at $5{ }^{\circ} \mathrm{C}$ in an aqueous buffer solution (sodium phosphate $100 \mathrm{mM}, \mathrm{pH}$ 6.0). As shown in Figure 5, bgl and CelDZ1 retained more than $70 \%$ of their initial activity after 24 days, while the residual activity of both GOx and HRP was found to be around 30\% of their initial activity. Other studies have also mentioned enhanced storage stability (up to 7 weeks during storage at $4{ }^{\circ} \mathrm{C}$ ) for individually immobilized GOx [43] and cellulase onto magnetic nanoparticles [44] as well as for bgl immobilized on modified magnetic nanoparticles [45]. Increased storage stability has also been reported for the co-immobilization of cellulase on magnetic nanoparticles, either with $\alpha$-amylase and pectinase or with pectinase and xylanase $[17,18]$. Hence, the increased storage stability of the four-enzyme magnetic nanobiocatalyst could be possibly attributed to the covalent linkage of enzymes onto the magnetic nanoparticles that protects the enzyme structure, preventing possible distortion effects on their active centers during storage in buffer solution [17]. However, HRP seems to be more sensitive to storage stability. This result is in agreement with a previous work [29], where the low storage stability of a bienzymatic biocatalyst constituted by GOx and HRP was likely imputable to HRP, whose immobilization is directly affected by many parameters [46], rather than the more robust GOx enzyme. It is worth mentioning that the storage stability of all the free enzyme forms was $10 \%$ lower than the co-immobilized enzymes, in the same conditions.

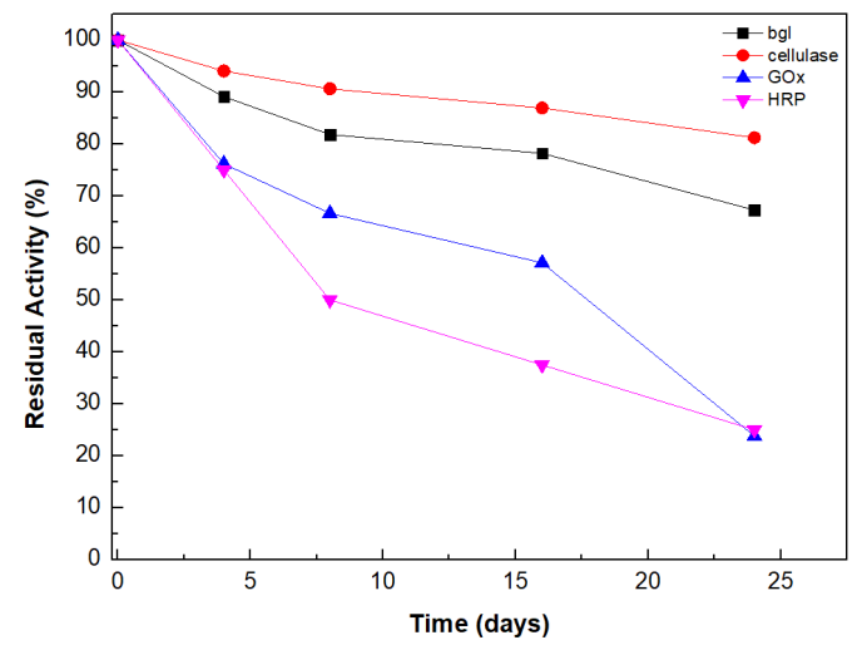

Figure 5. Storage stability studies of the four enzymes co-immobilized onto Aptes-functionalized MNPs during storage at $5{ }^{\circ} \mathrm{C}$ for 24 days. The activity of the first day was set to $100 \%$. 


\subsection{Reusability Studies}

In order to render the industrial implementation of immobilized multi-enzymatic systems viable, we should consider recycling of the immobilized nanobiocatalysts as a high priority [47]. So, the reusability of the four-enzyme magnetic complex was evaluated for five successive reaction cycles for hydrolysis of respective substrates of each enzyme in a batch mode (Figure 6). After each cycle, the co-immobilized system was separated by the use of an external magnet (Supplementary data, Figure S7), washed thrice with phosphate buffer (100 mM, pH 6.0) and added to fresh substrate solution to start a new reaction cycle. As can be seen in Figure 6, the residual activity of the reused multi-enzyme nanobiocatalyst decreased gradually after being repeatedly recycled for five consecutive cycles. However, all the enzymes retained more than $20 \%$ of their initial activity. The decline in residual activity could be attributed to many factors, such as the mechanical damage of the nanobiocatalyst during the recycling procedure along with product inhibition $[17,18]$. Similar results have been also reported for the immobilization of other cellulases onto magnetic nanoparticles [44], for the co-immobilization of bgl and glucose isomerase onto stellate macroporous silica nanospheres [48], as well as for the immobilization of GOx [49] and HRP [50] on magnetic nanoparticles.

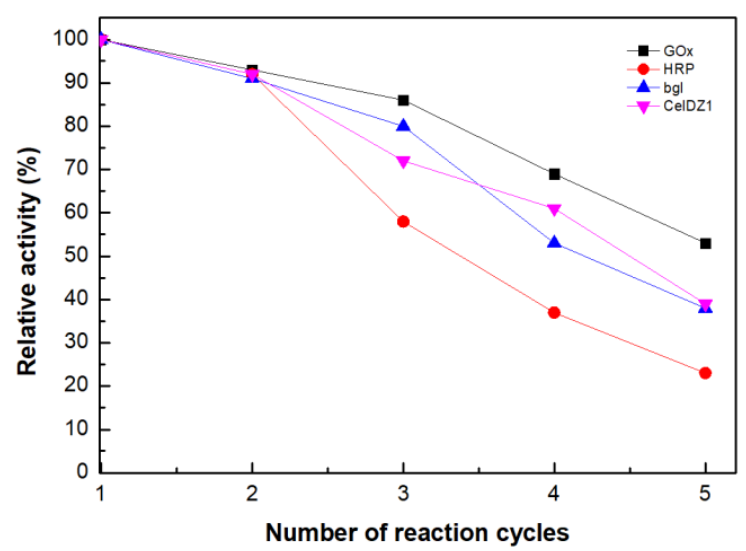

Figure 6. Reusability studies of the four-enzyme magnetic complex for five consecutive cycles. The activity of the first cycle was set to $100 \%$.

\subsection{Use of the Multi-Enzyme Magnetic Nanobiocatalyst in a Four-Step Cascade Reaction}

The catalytic performance of the prepared four-enzyme magnetic complex was assessed by its effectiveness in conducting a multi-step chain reaction involving the hydrolysis of cellulose. CelDZ1 hydrolyzes carboxymethylcellulose (CMC) into simpler sugar molecules, such as cellobiose, which can be subsequently hydrolyzed by bgl into glucose. The produced glucose serves in a next step as a substrate for GOx that oxidizes it to gluconic acid and $\mathrm{H}_{2} \mathrm{O}_{2}$. Finally, the last step of the cascade process involves the HRP-mediated reduction of $\mathrm{H}_{2} \mathrm{O}_{2}$ to $\mathrm{H}_{2} \mathrm{O}$ in the presence of a chromogenic substrate, 2,2'-Azino-bis (3-ethylbenzothiazoline-6-sulfonic acid) diammonium salt (ABTS), that turns into dark green in its oxidized form [41] (Figure 7). The oxidized form of ABTS $\left(\mathrm{ABTS}^{+}\right)$was confirmed by the characteristic peaks in absorption bands firstly at $405 \mathrm{~nm}$ and at $730 \mathrm{~nm}$ (Figure 8a) only after a lag time of $120 \mathrm{~min}$. The absorption peak at $730 \mathrm{~nm}$ continued to increase after the $120 \mathrm{~min}$ interval, while the color of the reaction in the test tube progressively turned from initially colorless to dark green (Figure $8 b$ ), indicating that all the steps of the cascade reaction were successful. Spectra were taken in the range of 400-800 nm over an extended period of time $(6 \mathrm{~h})$ at standard intervals to confirm the oxidation of ABTS. A temperature increase from $40{ }^{\circ} \mathrm{C}$ to $50{ }^{\circ} \mathrm{C}$ resulted in enhanced rate of the cascade reaction, as confirmed by the increment in absorption bands at 405 and $730 \mathrm{~nm}$ (Figure 8c). Finally, it is worth mentioning that the nanobiocatalyst could be reused for consecutive reaction cycles for the catalysis of the cascade reaction described above and its residual activity after five reaction cycles was about $15 \%$. 


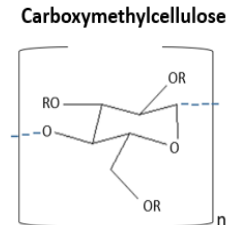

$\mathrm{R}=\mathrm{H}$ or $\mathrm{CH}_{2} \mathrm{CO}_{2} \mathrm{H}$

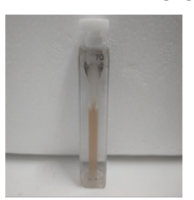

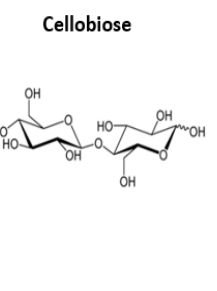

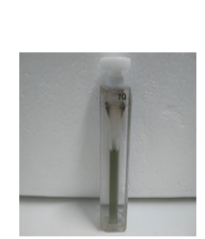

ABTS $\Longleftrightarrow$ ABTS

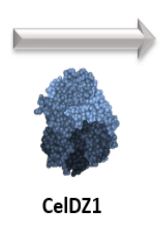

.

ABTS
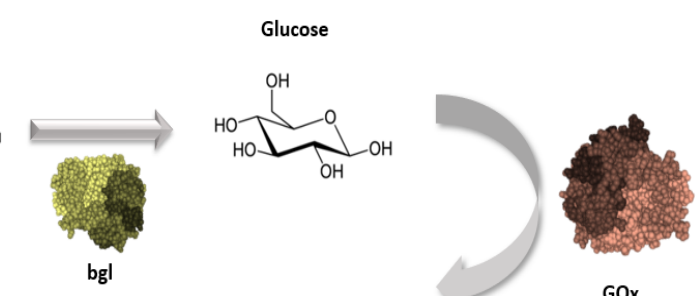

GOx

Figure 7. A schematically represented four-step cascade reaction for the hydrolysis of cellulose. In the first step, CelDZ1 hydrolyzes cellulose into cellobiose which further turns into glucose by bgl. The third step of the cascade process involves the oxidation of glucose to gluconic acid and $\mathrm{H}_{2} \mathrm{O}_{2}$. Finally, $\mathrm{H}_{2} \mathrm{O}_{2}$ acts as substrate for the HRP which reduces it to $\mathrm{H}_{2} \mathrm{O}$ in the presence of ABTS that progressively turns green.

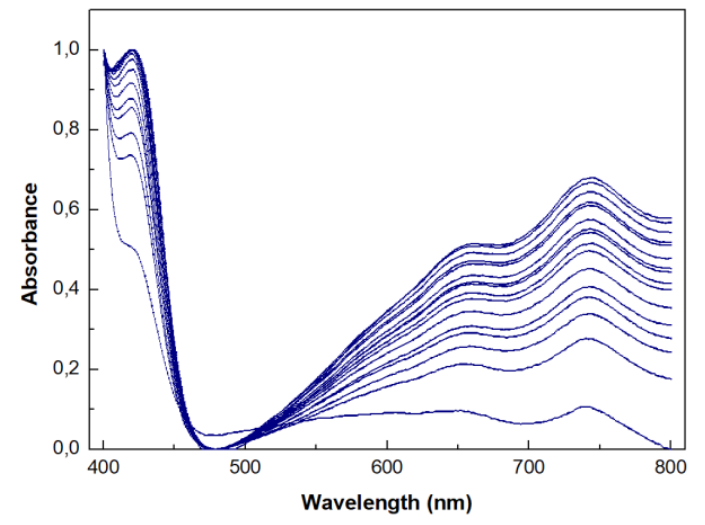

(a)

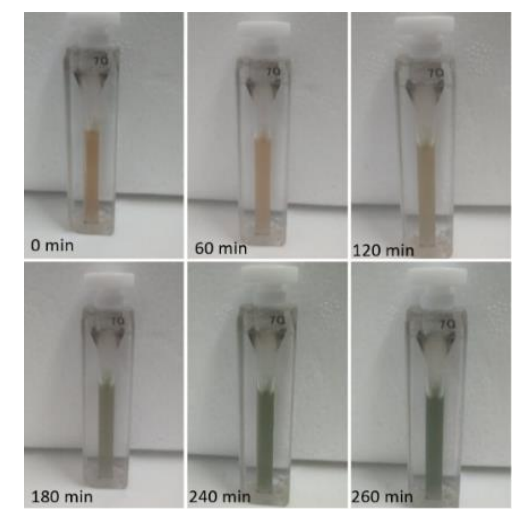

(b)

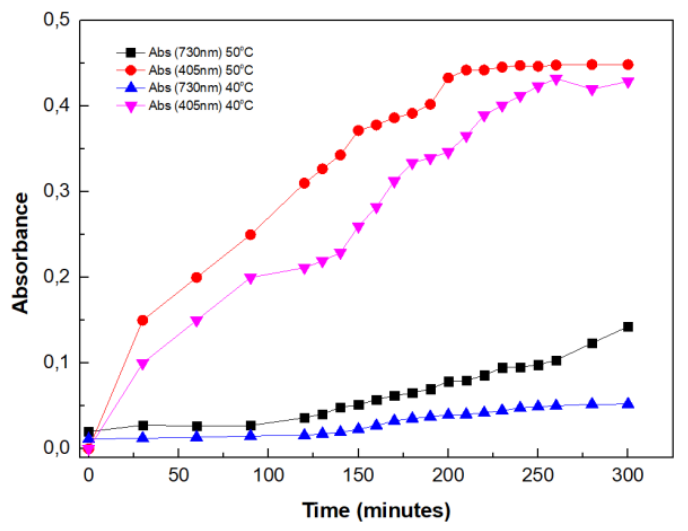

(c)

Figure 8. A cascade reaction catalyzed by the four-enzyme magnetic nanobiocatalyst for CMC hydrolysis. (a) Normalized time-dependent UV-Vis spectra recorded on solutions containing the four- 
enzyme magnetic nanobiocatalyst, $\mathrm{CMC}$ and $\mathrm{ABTS}$ at $50{ }^{\circ} \mathrm{C}$, showing increase in absorption peak at $730 \mathrm{~nm}\left(\mathrm{ABTS}^{+}\right)$over an extended period of time $(6 \mathrm{~h}),(\mathbf{b})$ Optical images showing aqueous mixture of CMC and ABTS at various incubation times ( $\mathrm{t}=0,60,120,180,240$ and $260 \mathrm{~min})$ at $50{ }^{\circ} \mathrm{C}$. The solution turns progressively green as oxidized ABTS is released at the final stage of the cascade reaction and (c) Time-dependent increase in absorption at $405 \mathrm{~nm}$ and $730 \mathrm{~nm}$ for the cascade reaction carried at $40{ }^{\circ} \mathrm{C}$ and $50^{\circ} \mathrm{C}$.

\section{Materials and Methods}

\subsection{Materials}

CelDZ1, a GH5 cellulase originally isolated from an Icelandic hot spring Thermoanaerobacterium isolate was recombinantly produced in Escherichia coli, purified and lyophilized (74 Units $\mathrm{mg}^{-1}$ ) as previously reported [27]. $\beta$-Glucosidase (bgl) from Thermotoga maritima (85 Units $\mathrm{mg}^{-1}$ ) was purchased from Megazyme (Chicago, IL, USA) and was used with no further purification. Glucose oxidase (GOx) from Aspergillus niger (135 Units $\mathrm{mg}^{-1}$ ) and Horseradish peroxidase (HRP) (148 Units $\mathrm{mg}^{-1}$ ) were purchased from Sigma-Aldrich (St. Louis, MO, USA) and were used with no further purification. 2,2' -Azino-bis (3-ethylbenzothiazoline-6-sulfonic acid) diammonium salt, (ABTS, $\geq 98 \%$ [HPLC]), glutaraldehyde solution (25\% v/v in $\left.\mathrm{H}_{2} \mathrm{O}\right)$, 3,5-dinitrosalicylic acid (DNSA), 4-nitrophenyl $\beta$-D-galactoside, (p-NPG, $\geq 98 \%$ [TLC]), D(+)-Glucose anhydrous, carboxymethylcellulose sodium salt (low viscosity, CMC) and (3-Aminopropyl)triethoxysilane (Aptes, 99\%) were also purchased from Sigma-Aldrich (St. Louis, MO, USA). All the other chemicals and reagents were of analytical grade and procured from reliable sources. Milli-Q water was used for the preparation of all the buffers and solutions.

\subsection{Methods}

All experiments were performed by triplicate and the values are given as mean values and experimental errors.

\subsubsection{Cellulase Isolation, Purification and Lyophilization}

CelDZ1 was produced recombinantly in E. coli cells and purified using imobilized metall affinity chromatography (IMAC) as described thoroughly previously [27]. Briefly, E. coli BL21 (DE3) cells carrying the recombinant plasmid pET-CelDZ1 were grown in selective LB broth. The overexpression of celDZ1 was induced by the addition of isopropyl thio- $\beta$-D-galactoside (IPTG) followed by overnight incubation. For CelDZ1 purification, the His-Tag Protein Purification Ni-NTA Agarose kit (QIAGEN) was used. Following optimization of the manufacturer's protocol, cells from an overnight culture were harvested, washed, re-suspended in equilibration buffer NPI10 (50 mM NaH${ }_{2} \mathrm{PO}_{4}, 300$ mM $\mathrm{NaCl}, 10 \mathrm{mM}$ imidazole) and lysed by brief sonication steps on ice. The cell extract was clarified by centrifugation and the supernatant was incubated at $60^{\circ} \mathrm{C}$ for $1 \mathrm{~h}$ to denature non-thermostable host proteins. The heat-treated extract was centrifuged again and the supernatant containing the recombinant protein was incubated under mild shaking with Ni-NTA agarose beads. The mixture was then loaded onto a polypropylene column, the flow-through was discarded and the column was washed with NPI20 wash buffer ( $50 \mathrm{mM} \mathrm{NaH}_{2} \mathrm{PO}_{4}, 300 \mathrm{mM} \mathrm{NaCl}, 20 \mathrm{mM}$ imidazole). CelDZ1 was eluted using NPI200 elution buffer (50 mM NaH $\mathrm{PO}_{4}, 300 \mathrm{mM} \mathrm{NaCl}, 20 \mathrm{mM}$ imidazole). Imidazole and buffer salts were removed from the protein preparation using an Amicon ${ }^{\circledR}$ Ultra Centrifugal Filter with a 30,000 molecular weight cutoff. The IMAC elution was loaded on the filter and washed with double distilled water in several centrifugation rounds. The purified protein was visualized by sodium dodecyl sulfate polyacrylamide gel electrophoresis (SDS-PAGE) (data not shown) and lyophilized. 


\subsubsection{Synthesis of Magnetic Nanoparticles}

In a typical synthesis, $1 \mathrm{~g}$ [Fe (Chloride tetrahydrate)] were dispersed in $80 \mathrm{~mL}$ oleylamine at $80^{\circ} \mathrm{C}$ for $30 \mathrm{~min}$, under continuous magnetic stirring. When the mixture became a clear solution, the temperature was raised to $250{ }^{\circ} \mathrm{C}$ for $1 \mathrm{~h}$. Then, the reaction mixture was allowed to cool to room temperature. The iron nanoparticles $\left(\gamma-\mathrm{Fe}_{2} \mathrm{O}_{3}\right)$ were washed and centrifuged three times $(6000 \mathrm{rpm}$, $10 \mathrm{~min})$; the first one with $50 \mathrm{~mL}$ ethanol and then with a $(10: 1 \mathrm{v} / \mathrm{v})$ ethanol:chloroform solution in order to remove the oleylamine and obtain pristine magnetic nanoparticles. The last centrifugation was conducted with ethanol and the precipitate was collected and left to dry at room temperature.

\subsubsection{Synthesis of Amino Functionalized Magnetic Nanoparticles}

A solution of $0.4 \mathrm{~g}$ Aptes in $1 \mathrm{~mL}$ of dry chloroform was added to a suspension of $70 \mathrm{mg} \gamma-\mathrm{Fe}_{2} \mathrm{O}_{3}$ in $16 \mathrm{~mL}$ of dry toluene. The suspension of magnetic nanoparticles in toluene was sonicated for $15 \mathrm{~min}$ in order to avoid aggregation. Then, the final mixture was refluxed for $72 \mathrm{~h}$ at $100{ }^{\circ} \mathrm{C}$. The solid was filtered and washed by dry chloroform $(6000 \mathrm{rpm}, 10 \mathrm{~min})$ and dried in vacuum. A Schematic representation of the final functionalized nanoparticle is displayed in the following Figure 9.

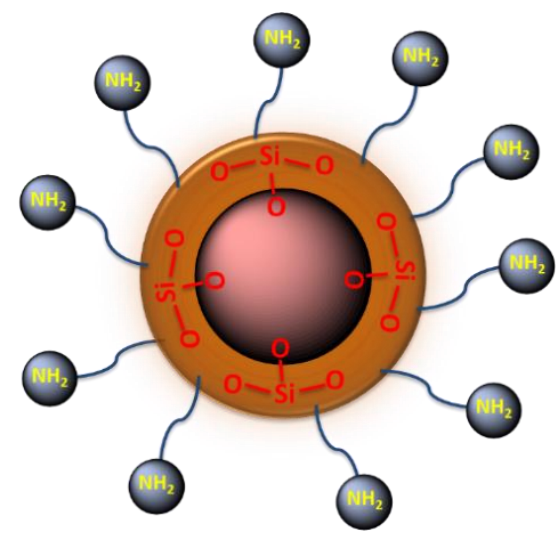

Figure 9. Schematic representation of amino-functionalized magnetic nanoparticles.

\subsubsection{Characterization of the Amino-Functionalized Magnetic Nanoparticles}

X-ray Diffraction $(\mathrm{XRD})$

XRD patterns were collected on a D8 Avance Bruker diffractometer by using Cu Ka radiation $(40 \mathrm{kV}, 40 \mathrm{~mA})$ and a secondary beam graphite monochromator.

Atomic Force Microscopy (AFM)

To confirm the size of the $\gamma$ - $\mathrm{Fe}_{2} \mathrm{O}_{3}$ nanoparticles, atomic force microscopy (AFM) images were collected in tapping mode with a Bruker Multimode 3D Nanoscope (Ted Pella Inc., Redding, CA, USA) using a micro fabricated silicon cantilever type TAP-300G, with a tip radius of $<10 \mathrm{~nm}$ and a force constant of approximately $20-75 \mathrm{~N} \mathrm{~m}^{-1}$.

\subsubsection{Preparation of Four-Enzyme Magnetic Nanobiocatalyst}

CelDZ1, bgl, GOx and HRP were covalently co-immobilized onto the surface of aminofunctionalized magnetic nanoparticles (MNPs) employing the glutaraldehyde cross-linking agent, which links the $\mathrm{NH}_{2}$ groups of the nanomaterials with the free amino groups of the enzymes $[30,51]$. In a typical procedure, $15 \mathrm{mg}$ of nanomaterial were dispersed in sodium phosphate buffer $(20 \mathrm{~mL}$, $100 \mathrm{mM}, \mathrm{pH} 6.0)$ in the presence of $0.36 \mathrm{~mL}$ Tween-20 (1\% v/v) and the mixture was incubated in an ultrasonic bath for $30 \mathrm{~min}$. After $30 \mathrm{~min}$, the cross-linker glutaraldehyde $(10 \% \mathrm{v} / \mathrm{v})$ was added and the mixture was allowed to shake for $30 \mathrm{~min}$ under stirring at room temperature $(30 \pm 2)$. Thorough 
centrifugation followed for removing the glutaraldehyde excess. The activated nanoparticles were re-dispersed in sodium phosphate buffer $(10 \mathrm{~mL}, 100 \mathrm{mM}, \mathrm{pH}$ 6.0) and the enzyme cocktail (total protein content of $15 \mathrm{mg}$ ) containing CelDZ1, bgl, GOx and HRP (in a typical mass ratio of 1:1:1:3) was added into the solution. Then the mixture was incubated for $2 \mathrm{~h}$ with constant shaking at $150 \mathrm{rpm}$. After cross-linking, the co-immobilized enzymes were separated with magnet, washed thrice with sodium phosphate buffer (100 mM, pH 6.0), to remove any physical adsorbed amount of protein and stored at $4{ }^{\circ} \mathrm{C}$. The prepared nanobiocatalyst was used as magnetic four-enzyme nanobiocatalyst. In order to attain the maximum activity recoveries of all the enzymes we examined several parameters of the immobilization procedure, such as the glutaraldehyde concentration $(2.5 \%, 5 \%, 10 \%, 15 \%$ and $20 \%)$, the incubation time $(1 \mathrm{~h}, 2 \mathrm{~h}, 4 \mathrm{~h}$ and $20 \mathrm{~h})$ and the mass ratio of MNPs to protein content $(0.5: 1$, 1:1 and 2:1) by one factor at a time. The activities of enzymes were expressed as activity recovery (\%), which is determined as the percent activity of each immobilized enzyme (U) divided by the total initial activity of each enzyme. Also, CelDZ1, bgl, GOx and HRP were immobilized separately (individually) onto amino-functionalized magnetic nanoparticles using glutaraldehyde as the cross-linker. The immobilization percentage was determined by the Bradford assay [52] through the difference of the protein concentration in the supernatant before and after the immobilization. All experiments were carried out in triplicate.

\subsubsection{Characterization of the Four-Enzyme Magnetic Nanobiocatalyst}

\section{Fourier-Transform Infrared Spectroscopy (FTIR)}

In order to confirm the characteristic functional peaks of amino functionalized magnetic nanoparticles and four-enzyme co-immobilized magnetic nanoparticles a FTIR-8400 infrared spectrometer (Shimadzu, Tokyo, Japan) equipped with a deuterated triglycine sulfate (DTGS) detector was used. All spectra were recorded within $400-4.000 \mathrm{~cm}^{-1}$ range and on average of 32 scans.

X-ray Photoelectron Spectroscopy (XPS)

X-ray photoelectron spectroscopy (XPS) measurements were performed in ultrahigh vacuum at a base pressure of $2 \times 10^{-10}$ mbar with a SPECS GmbH spectrometer equipped with a monochromatic MgKa source $(\mathrm{hv}=1253.6 \mathrm{eV})$ and a Phoibos-100 hemispherical analyzer (SPECSGROUP, Berlin, Germany). The spectra were collected in normal emission and energy resolution was set to $1.16 \mathrm{eV}$ to minimize measuring time. Spectral analysis included a Shirley background subtraction and a peak deconvolution employing mixed Gaussian-Lorentzian functions, in a least squares curve-fitting program (WinSpec) developed at the Laboratoire Interdisciplinaire de Spectroscopie Electronique, University of Namur, Belgium.

\subsubsection{Enzyme Assays}

Enzymatic activities of the free, individually immobilized and co-immobilized CelDZ1 were determined by the amount of reducing sugars released from soluble cellulose (CMC) by 3,5-dinitrosalicylic acid (DNS) method [53]. Briefly, $3 \mu \mathrm{g} / \mathrm{mL}$ of native enzyme (or equivalent amount of individually immobilized or co-immobilized CelDZ1) was added to a soluble cellulose solution $(1 \% w / v$ in $100 \mathrm{mM}$ sodium acetate buffer, $\mathrm{pH} 5.0)$ in a test tube and the mixture was incubated at $50{ }^{\circ} \mathrm{C}$ for $15 \mathrm{~min}$. In a following step, an equal volume of DNSA was added to terminate the reaction and then the reaction mixture was boiled for $5 \mathrm{~min}$. Then the samples were collected, diluted with distilled water and cooled in an ice bath. The released reducing sugar (estimated as glucose) was measured spectrophotometrically at $540 \mathrm{~nm}$ (Shimadzu, Tokyo, Japan). One unit of cellulase activity was defined as the amount of the enzyme required for releasing one $\mu$ mole of reducing sugars (glucose) at optimum conditions.

The enzymatic assays of the other three enzymes (bgl, GOx and HRP) in free, individually immobilized or co-immobilized form were performed on a UV-Vis spectrophotometer equipped with a 
Peltier temperature controller (Shimadzu, Tokyo, Japan). The activity of $\beta$-glucosidase was estimated by using $\mathrm{p}-\mathrm{NPG}$ as a substrate. Under optimum conditions, $\beta$-glucosidase hydrolyzes $\mathrm{p}$-NPG into $\mathrm{p}-\mathrm{NP}$ (colored product) and glucose. For the activity assay, $0.12 \mu \mathrm{g} / \mathrm{mL}$ of free enzyme solution (or equivalent amount of individually immobilized and co-immobilized bgl) was mixed with $2.0 \mathrm{mM}$ p-NPG in $100 \mathrm{mM}$ citrate phosphate buffer, $\mathrm{pH} 6.5$ at $50{ }^{\circ} \mathrm{C}$. The reaction was followed by measuring the increase in absorbance of p-NP at $410 \mathrm{~nm}$ using a UV/Vis spectrophotometer (Shimadzu, Tokyo, Japan). Absorption values are taken every one minute for a total of five minutes and were converted to $\mathrm{p}-\mathrm{NP}$ concentration using the molar extinction coefficient of p-NP at $410 \mathrm{~nm}$ [54]. Enzymatic activity was estimated as the amount ( $\mu$ moles) of p-NP transformed per minute.

HRP utilizes hydrogen peroxide to convert chromogenic substrates (e.g., ABTS). Hence, the study of horseradish peroxidase activity is based on the oxidation reaction of ABTS to $\mathrm{ABTS}^{+}$. The increase in absorbance of $\mathrm{ABTS}^{+}$is measured at $405 \mathrm{~nm}$. Briefly, $0.5 \mathrm{mM}$ ABTS are mixed with $0.1 \mathrm{mM}$ hydrogen peroxide and $0.4 \mu \mathrm{g} / \mathrm{mL}$ of free enzyme solution (or equivalent amount of individually immobilized and co-immobilized HRP) to a final total volume of $1 \mathrm{~mL}$ supplemented with $100 \mathrm{mM}$ sodium phosphate buffer, $\mathrm{pH}$ 6.0. Absorbance values are taken every one minute for a total of $10 \mathrm{~min}$ and were converted to ABTS concentration using the molar extinction coefficient of oxidized ABTS at $405 \mathrm{~nm}$ [55]. Enzymatic activity was determined as the amount ( $\mu$ moles) of ABTS transformed per minute.

The study of glucose oxidase activity is based on its coupling reaction with the horseradish peroxidase enzyme. Specifically, GOx utilizes D-glucose as a substrate converting it to D-gluconoS-lactone and hydrogen peroxide. HRP then uses hydrogen peroxide to convert ABTS to ABTS ${ }^{+}$. The reaction is followed by measuring the increase in absorbance of $\mathrm{ABTS}^{+}$at $405 \mathrm{~nm}$. Absorption values are taken every one minute for a total of five minutes. Briefly, $0.5 \mu \mathrm{g} / \mathrm{mL}$ of free enzyme solution (or equivalent amount of individually immobilized and co-immobilized GOx) is mixed with $250 \mathrm{mM}$ glucose solution, $0.4 \mathrm{mM}$ ABTS and $0.3 \mu \mathrm{g} / \mathrm{mL}$ HRP. Enzymatic activity was determined as the amount ( $\mu$ moles) of ABTS transformed per min.

\subsubsection{Thermal Inactivation Kinetics Studies}

Thermal stability of CelDZ1, bgl, GOx and HRP in free and co-immobilized form was studied by incubating in the temperature range of $30-60{ }^{\circ} \mathrm{C}$ for celDZ1 and GOx, $30-50{ }^{\circ} \mathrm{C}$ for $\mathrm{HRP}$ as it is rapidly inactivated at temperatures over $50^{\circ} \mathrm{C}$ and $70-90^{\circ} \mathrm{C}$ for bgl as it is considered a highly thermostable enzyme [35]. The samples were collected at standard minute intervals for a total of $120 \mathrm{~min}$, cooled quickly and then assayed for the respective enzyme activities as described above. A semi-log plot of residual activity of each enzyme against time was plotted to determine the slope as the inactivation rate constant $\left(\mathrm{k}_{\mathrm{d}}\right)$. The half-life $\left(\mathrm{t}_{1 / 2}\right)$ is the time required to reduce the activity to $50 \%$ of the original activity and was evaluated as:

$$
\mathrm{t}_{1 / 2}=0.693 / \mathrm{k}_{\mathrm{d}}
$$

Further, activation energy for deactivation $\left(E_{d}\right)$ of the free and immobilized form of enzymes was determined from the slope of $\ln \left(\mathrm{k}_{\mathrm{d}}\right)$ versus $1 / \mathrm{T}$ [T corresponds to the absolute temperature $(\mathrm{K})$ ] from the Arrhenius plots as:

$$
\text { Slope }=-E_{\mathrm{d}} / \mathrm{R}
$$

where $R$ corresponds to the gas constant $(R=8.314 \mathrm{~J} / \mathrm{mol} / \mathrm{K})$.

\subsubsection{Determination of Thermodynamic Parameters}

The changes in the thermodynamic behavior after heat treatment of the four enzymes before and after co-immobilization were evaluated by Eyring's transition state theory. The enthalpy for activation $\left(\Delta \mathrm{H}^{\circ}\right)$ was determined by the following equation:

$$
\Delta \mathrm{H}^{\circ}=\mathrm{E}_{\mathrm{d}}-\mathrm{RT},
$$


where $\mathrm{R}$ corresponds to the gas constant $(\mathrm{R}=8.314 \mathrm{~J} / \mathrm{mol} / \mathrm{K})$ and $\mathrm{T}$ to the absolute temperature $(\mathrm{K})$. The free energy for activation $\left(\Delta \mathrm{G}^{\circ}\right)$ was determined as:

$$
\Delta \mathrm{G}^{\circ}=-\mathrm{RT} \ln \left(\mathrm{k}_{\mathrm{d}} / \mathrm{k}_{\mathrm{B}} \times \mathrm{h} / \mathrm{T}\right),
$$

where $\mathrm{k}_{\mathrm{B}}$ represents the Boltzman constant $\left(\mathrm{k}_{\mathrm{B}}=1.38 \times 10^{-23} \mathrm{~J} / \mathrm{K}\right)$, while h corresponds to Planck's constant $\left(\mathrm{h}=11.04 \times 10^{-34} \mathrm{~J} \mathrm{~min}\right)$. Finally, the entropy for activation $\left(\Delta \mathrm{S}^{\circ}\right)$ was calculated by the difference between $\Delta \mathrm{H}^{\circ}$ and $\Delta \mathrm{G}^{\circ}$ divided by the absolute temperature $(\mathrm{K})$ as:

$$
\Delta S^{\circ}=\left(\Delta H^{\circ}-\Delta G^{\circ}\right) / T .
$$

\subsubsection{Determination of Michaelis-Menten Kinetic Parameters}

The kinetic parameters $\left(\mathrm{K}_{\mathrm{m}}, \mathrm{V}_{\mathrm{max}}\right)$ of free, individually immobilized and co-immobilized form of CelDZ1, bgl, GOx and HRP were determined by measuring the initial reaction rates for each form by varying concentrations of $\mathrm{CMC}$, p-NPG, glucose and $\mathrm{H}_{2} \mathrm{O}_{2}$ respectively at $50{ }^{\circ} \mathrm{C}$ as described above. The concentrations of CMC, p-NPG, glucose and $\mathrm{H}_{2} \mathrm{O}_{2}$ were ranged from 0.1 to $3.5 \% w / v, 0.05$ to $15 \mathrm{mM}, 1$ to $25 \mathrm{mM}$ and 0.015 to $0.275 \mathrm{mM}$, respectively. HRP assays were carried out in the presence of $3 \mathrm{mM}$ ABTS, while GOx was assayed in the presence of $2.5 \mathrm{mM}$ ABTS. The Michaelis-Menten constant $\left(\mathrm{K}_{\mathrm{m}}\right)$ and maximum velocity $\left(\mathrm{V}_{\max }\right)$ were calculated from non-linear regression fitting of the initial reaction rates corresponding to different substrate concentrations by the EnzFitter (Biosoft) software.

\subsubsection{Reusability Studies}

The reaction was carried out for the specified time at $50{ }^{\circ} \mathrm{C}$ and activity was measured by using the respective substrates ( $C M C$, p-NPG, glucose and $\mathrm{H}_{2} \mathrm{O}_{2}$ ). After each reaction cycle, the four-enzyme nanobiocatalyst was separated using an external magnetic field, washed thoroughly with sodium phosphate buffer (100 mM, pH 6.0) and re-suspended in fresh substrate solution to start a new reaction cycle. The process was repeated for five consecutive cycles. The activity of each enzyme after each cycle was estimated in terms of residual activity by considering the activity of the first cycle to be $100 \%$.

\subsubsection{Storage Stability Studies}

The storage stability of the co-immobilized form of the enzymes was estimated during storage at $5{ }^{\circ} \mathrm{C}$. The activity of each sample was evaluated after different day intervals for a total of 24 days. The activity of each enzyme after standard day intervals was estimated in terms of residual activity using respective assay by considering the activity of the first day to be $100 \%$.

\subsubsection{Application of the Magnetic Nanobiocatalyst for Cellulose Hydrolysis in a Four-Step} Cascade Reaction

The catalytic performance of the magnetic four-enzyme nanobiocatalyst was estimated with regard to a four-step cascade reaction involving the CelDZ1-mediated hydrolysis of soluble cellulose (CMC) to cellobiose that was consecutively hydrolyzed by bgl to D-glucose. D-glucose was successively oxidized by GOx to gluconic acid and $\mathrm{H}_{2} \mathrm{O}_{2}$, followed by reduction of $\mathrm{H}_{2} \mathrm{O}_{2}$ to $\mathrm{H}_{2} \mathrm{O}$ by HRP in the presence of an electron donor (ABTS). Briefly, $0.3 \mathrm{mg} / \mathrm{mL}$ of the magnetic nanobiocatalyst were added into $1 \% w / v$ CMC solution containing $3 \mathrm{mM}$ ABTS in $100 \mathrm{mM}$ sodium phosphate buffer, $\mathrm{pH} 6.0$ at $50{ }^{\circ} \mathrm{C}$. The initially colorless substrate solution gradually turned green due to oxidation of ABTS and formation of the corresponding radical cation. The reaction was followed by measuring the increase in absorbance at $730 \mathrm{~nm}\left(\mathrm{ABTS}^{+}\right)$at a UV-Vis photometer equipped with a Peltier temperature controller (Shimadzu, Tokyo, Japan). 


\section{Conclusions}

In the present work, we have shown for the first time that the simultaneous covalent co-immobilization of four enzymes onto magnetic nanoparticles can lead to the development of robust nanoassemblies able to conduct multi-step cascade reactions. The prepared nanobiocatalyst was able to catalyze the hydrolysis of cellulose to glucose along with a simple, direct and continuous monitoring of the reaction progress. Amino-functionalized magnetic nanoparticles proved to be an effective platform for the four-enzyme biocatalyst produced by the co-immobilization of CelDZ1, bgl, GOx and HRP. Although the co-immobilization process leads to some loss in enzymatic activities, the resultant nanobiocatalyst exhibited enhanced thermal stability and higher $\Delta \mathrm{H}^{\circ}, \Delta \mathrm{G}^{\circ}$ and $\Delta \mathrm{S}^{\circ}$ values than the native enzymes over a wide range of incubation temperatures. Moreover, the ease of manipulating magnetic biocatalysts with the use of an external magnetic field can overcome commonplace obstacles concerning their handling and separation. The highly efficient concerted mechanisms of cascade reactions, characterized by selectivity, absence of hazardous chemicals, low energy and no need to isolate the reaction intermediates, endorse that co-immobilization of multiple enzymes onto nanosupports can provide an efficient way to design in vitro multi-enzymatic nanoassemblies for cascade reactions. Based on this work, we anticipate that future work will be directed towards the development of innovative multi-enzymatic systems for a wide range of biocatalysts applications.

Supplementary Materials: The following are available online at http://www.mdpi.com/2073-4344/9/12/995/s1, Table S1: Immobilization yield of CelDZ1, bgl, GOx and HRP individually immobilized on amino-functionalized magnetic nanoparticles; Table S2: Thermal inactivation kinetics parameters of free and co-immobilized bgl at 70, 80 and $90^{\circ} \mathrm{C}$; Table S3: Thermal inactivation kinetics parameters of free and co-immobilized HRP at 30, 40 and $50^{\circ} \mathrm{C}$; Table S4: Thermal inactivation kinetics parameters of free and co-immobilized cellulase and GOx at 40, 50 and $60{ }^{\circ} \mathrm{C}$; Table S5: Thermodynamic parameters of free and co-immobilized bgl at 70,80 and $90^{\circ} \mathrm{C}$; Table S6: Thermodynamic parameters of free and co-immobilized HRP at 30,40 and $50^{\circ} \mathrm{C}$; Table S7: Thermodynamic parameters of free and co-immobilized cellulase and GOx at 40,50 and $60^{\circ} \mathrm{C}$; Figure S1: XRD patterns of maghemite $\gamma-\mathrm{Fe}_{2} \mathrm{O}_{3}$ nanoparticles obtained by thermolysis method; Figure S2: AFM height image (a) and cross section analysis (b) of $\gamma-\mathrm{Fe}_{2} \mathrm{O}_{3}$ magnetic nanoparticles; Figure S3: Arrhenius plot for the inactivation of free form (FF) and co-immobilized form (CIF) of celDZ1; Figure S4: Arrhenius plot for the inactivation of free form (FF) and co-immobilized form (CIF) of bgl; Figure S5: Arrhenius plot for the inactivation of free form (FF) and co-immobilized form (CIF) of GOx; Figure S6: Arrhenius plot for the inactivation of free and co-immobilized HRP; Figure S7: Nanobiocatalyst's magnetic separation by the use of an external magnetic field.

Author Contributions: A.G. performed immobilization and biocatalytic experiments, results interpretation and manuscript writing; M.P. contributed to results analysis and interpretation; N.C. and K.S. performed AFM. XRD and XPS experiments and contributed to result analysis; D.Z. and G.S. performed the production and purification of cellulase and reviewed the manuscript; D.G. contributed to results interpretation and reviewed the manuscript; H.S. contributed to the overall design of the experiments, results interpretation and manuscript writing.

Funding: This work was supported by the project "Synthetic Biology: from omics technologies to genomic engineering (OMIC-ENGINE)" (MIS 5002636), which is implemented under the Action "Reinforcement of the Research and Innovation Infrastructure," funded by the Operational Program "Competitiveness, Entrepreneurship and Innovation" (NSRF 2014-2020) and co-financed by Greece and the European Union (European Regional Development Fund).

Conflicts of Interest: The authors declare no conflict of interest. The funders had no role in the design of the study; in the collection, analyses or interpretation of data; in the writing of the manuscript or in the decision to publish the results.

\section{References}

1. Min, K.; Yoo, Y.J. Recent progress in nanobiocatalysis for enzyme immobilization and its application. Biotechnol. Bioprocess Eng. 2014, 19, 553-567. [CrossRef]

2. Choi, J.; Han, S.; Kim, H. Industrial applications of enzyme biocatalysis: Current status and future aspects. Biotechnol. Adv. 2015, 33, 1443-1454. [CrossRef] [PubMed]

3. Jia, F.; Narasimhan, B.; Mallapragada, S. Materials-Based Strategies for Multi-Enzyme Immobilization and Co-Localization: A Review. Biotechnol. Bioeng. 2014, 111, 209-222. [CrossRef] [PubMed]

4. Filice, M.; Palomo, J.M. Cascade reactions catalyzed by bionanostructures. ACS Catal. 2014, 4, 1588-1598. [CrossRef] 
5. Sperl, J.M.; Sieber, V. Multienzyme Cascade Reactions-Status and Recent Advances. ACS Catal. 2018, 8, 2385-2396. [CrossRef]

6. Velasco-Lozano, S.; López-Gallego, F. Wiring step-wise reactions with immobilized multi-enzyme systems. Biocatal. Biotransform. 2018, 36, 184-194. [CrossRef]

7. Giannakopoulou, A.; Gkantzou, E.; Polydera, A.; Stamatis, H. Multienzymatic Nanoassemblies: Recent Progress and Applications. Trends Biotechnol. 2019. [CrossRef]

8. Ji, Q.; Wang, B.; Tan, J.; Zhu, L.; Li, L. Immobilized multienzymatic systems for catalysis of cascade reactions. Process Biochem. 2016, 51, 1193-1203. [CrossRef]

9. Hwang, E.T.; Lee, S. Multienzymatic Cascade Reactions via Enzyme Complex by Immobilization. ACS Catal. 2019, 9, 4402-4425. [CrossRef]

10. Meryam Sardar, R.A. Enzyme Immobilization: An Overview on Nanoparticles as Immobilization Matrix. Biochem. Anal. Biochem. 2015, 4, 178. [CrossRef]

11. Gupta, M.N.; Kaloti, M.; Kapoor, M.; Solanki, K. Nanomaterials as matrices for enzyme immobilization. Artif. Cells Blood Substit. Biotechnol. 2011, 39, 98-109. [CrossRef] [PubMed]

12. Patila, M.; Kouloumpis, A.; Gournis, D.; Rudolf, P.; Stamatis, H. Laccase-functionalized graphene oxide assemblies as efficient nanobiocatalysts for oxidation reactions. Sensors (Switz.) 2016, 16, 287. [CrossRef] [PubMed]

13. Chatzikonstantinou, A.V.; Gkantzou, E.; Gournis, D.; Patila, M.; Stamatis, H. Stabilization of Laccase through Immobilization on Functionalized GO-Derivatives. Enzyme Nanoarchitectures: Enzymes Armored with Graphene, 1st ed.; Kumar, C.V., Ed.; Elsevier Inc.: Amsterdam, The Netherlands, 2018; Volume 609, pp. 47-81.

14. Chen, M.; Zeng, G.; Xu, P.; Lai, C.; Tang, L. How Do Enzymes 'Meet' Nanoparticles and Nanomaterials? Trends Biochem. Sci. 2017, 42, 914-930. [CrossRef] [PubMed]

15. Pavlidis, I.V.; Patila, M.; Bornscheuer, U.T.; Gournis, D.; Stamatis, H. Graphene-based nanobiocatalytic systems: Recent advances and future prospects. Trends Biotechnol. 2014, 32, 312-320. [CrossRef]

16. Bilal, M.; Zhao, Y.; Rasheed, T.; Iqbal, H.M.N. Magnetic nanoparticles as versatile carriers for enzymes immobilization: A review. Int. J. Biol. Macromol. 2018, 120, 2530-2544. [CrossRef]

17. Sojitra, U.V.; Nadar, S.S.; Rathod, V.K. A magnetic tri-enzyme nanobiocatalyst for fruit juice clarification. Food Chem. 2016, 213, 296-305. [CrossRef]

18. Muley, A.B.; Thorat, A.S.; Singhal, R.S.; Harinath Babu, K. A tri-enzyme co-immobilized magnetic complex: Process details, kinetics, thermodynamics and applications. Int. J. Biol. Macromol. 2018, 118, 1781-1795. [CrossRef]

19. Orfanakis, G.; Patila, M.; Catzikonstantinou, A.V.; Lyra, K.-M.; Kouloumpis, A.; Spyrou, K.; Katapodis, P.; Paipetis, A.; Rudolf, P.; Gournis, D.; et al. Hybrid Nanomaterials of Magnetic Iron Nanoparticles and Graphene Oxide as Matrices for the Immobilization of $\beta$-Glucosidase: Synthesis, Characterization, and Biocatalytic Properties. Front. Mater. 2018, 5, 11. [CrossRef]

20. Jia, F.; Mallapragada, S.K.; Narasimhan, B. Multienzyme Immobilization and Colocalization on Nanoparticles Enabled by DNA Hybridization. Ind. Eng. Chem. Res. 2015, 54, 10212-10220. [CrossRef]

21. Wang, S.Z.; Zhang, Y.H.; Ren, H.; Wang, Y.L.; Jiang, W.; Fang, B.S. Strategies and perspectives of assembling multi-enzyme systems. Crit. Rev. Biotechnol. 2017, 37, 1024-1037. [CrossRef]

22. Wheeldon, I.; Minteer, S.D.; Banta, S.; Barton, S.C.; Atanassov, P.; Sigman, M. Substrate channelling as an approach to cascade reactions. Nat. Chem. 2016, 8, 299-309. [CrossRef] [PubMed]

23. Zhang, Y.H.P. Substrate channeling and enzyme complexes for biotechnological applications. Biotechnol. Adv. 2011, 29, 715-725. [CrossRef] [PubMed]

24. Poshyvailo, L.; Von Lieres, E.; Kondrat, S. Does metabolite channeling accelerate enzyme-catalyzed cascade reactions? PLoS ONE 2017, 12, e0172673. [CrossRef] [PubMed]

25. Cho, E.J.; Jung, S.; Kim, H.J.; Lee, Y.G.; Nam, K.C.; Lee, H.J.; Bae, H.J. Co-immobilization of three cellulases on Au-doped magnetic silica nanoparticles for the degradation of cellulose. Chem. Commun. 2012, 48, 886-888. [CrossRef] [PubMed]

26. Chen, Q.; Liu, D.; Wu, C.; Yao, K.; Li, Z.; Shi, N.; Wen, F.; Gates, I.D. Co-immobilization of cellulase and lysozyme on amino-functionalized magnetic nanoparticles: An activity-tunable biocatalyst for extraction of lipids from microalgae. Bioresour. Technol. 2018, 263, 317-324. [CrossRef] 
27. Zarafeta, D.; Kissas, D.; Sayer, C.; Gudbergsdottir, S.R. Discovery and Characterization of a Thermostable and Highly Halotolerant GH5 Cellulase from an Icelandic Hot Spring Isolate. PLoS ONE 2016, 11, e0146454. [CrossRef]

28. Chen, S.; Wen, L.; Svec, F.; Lv, Y. Magnetic metal-organic frameworks as scaffolds for spatial co-location and positional assembly of multi-enzyme systems enabling enhanced cascade biocatalysis. RSC Adv. 2017, 7, 21205-21213. [CrossRef]

29. Pitzalis, F.; Monduzzi, M.; Salis, A. A bienzymatic biocatalyst constituted by glucose oxidase and Horseradish peroxidase immobilized on ordered mesoporous silica. Microporous Mesoporous Mater. 2017, 241, 145-154. [CrossRef]

30. Barbosa, O.; Ortiz, C.; Berenguer-Murcia, Á.; Torres, R.; Rodrigues, R.C.; Fernandez-Lafuente, R. Glutaraldehyde in bio-catalysts design: A useful crosslinker and a versatile tool in enzyme immobilization. RSC Adv. 2014, 4, 1583-1600. [CrossRef]

31. Xu, Y.; Zhou, Y.; Ma, W.; Wang, S. A Fluorescent Sensor for Zinc Detection and Removal Based on Core-Shell

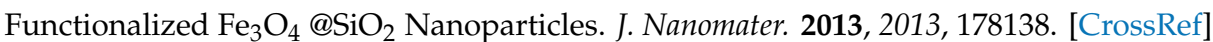

32. Bayat, A.; Shakourian-fard, M.; Ehyaei, N. A magnetic supported iron complex for selective oxidation of sulfides to sulfoxides using 30\% hydrogen peroxide at room temperature. RSC Adv. 2014, 4, 44274-44281. [CrossRef]

33. Majoul, N.; Aouida, S.; Bessaïs, B. Progress of porous silicon APTES-functionalization by FTIR investigations. Appl. Surf. Sci. 2015, 331, 388-391. [CrossRef]

34. Tawil, N.; Sacher, E.; Boulais, E.; Mandeville, R.; Meunier, M. X-ray Photoelectron Spectroscopic and Transmission Electron Microscopic Characterizations of Bacteriophage-Nanoparticle Complexes for Pathogen Detection. J. Phys. Chem. C 2013, 117, 20656-20665. [CrossRef]

35. Gupta, P.; Verma, S.; Vakhlu, J. Comparative Analysis of B -Glucosidases Thermostability: Differences in Amino Acids Composition and Distribution among Mesostable and Thermostable B -Glucosidases. J. Adv. Bioinform. Appl. Res. 2014, 5, 215-227.

36. Salgaonkar, M.; Nadar, S.S.; Rathod, V.K. Combi-metal organic framework (Combi-MOF) of $\alpha$-amylase and glucoamylase for one pot starch hydrolysis. Int. J. Biol. Macromol. 2018, 113, 464-475. [CrossRef] [PubMed]

37. Henriques, R.O.; Bork, J.A.; Fernandez-Lorente, G.; Guisan, J.M.; Furigo, A.; de Oliveira, D.; Pessela, B.C. Co-immobilization of lipases and B-D-galactosidase onto magnetic nanoparticle supports: Biochemical characterization. Mol. Catal. 2018, 453, 12-21. [CrossRef]

38. Eze, S.O.O.; Chilaka, F.C.; Nwanguma, B.C. Studies on Thermodynamics and Kinetics of Thermo-Inactivation of Some Quality-Related Enzymes in White Yam (Dioscorea rotundata). J. Thermodyn. Catal. 2010. [CrossRef]

39. Monteiro, P.; Aliakbarian, B.; Ximenes, E.; Filho, F.; Oliveira, P.; Pessoa, A.; Converti, A.; Perego, P. Kinetic and thermodynamic studies of a novel acid protease from Aspergillus foetidus. Int. J. Biol. Macromol. 2015, 81, 17-21. [CrossRef]

40. De Oliveira, R.L.; da Silva, O.S.; Converti, A.; Porto, T.S. Thermodynamic and kinetic studies on pectinase extracted from Aspergillus aculeatus: Free and immobilized enzyme entrapped in alginate beads. J. Biological. Macromol. 2018, 115, 1088-1093. [CrossRef]

41. Farrugia, T.; Perriman, A.W.; Sharma, K.P.; Mann, S. Multi-enzyme cascade reactions using protein -polymer surfactant self-standing films. Chem. Commun. 2017, 53, 2094-2097. [CrossRef]

42. Rezaei, S.; Landarani-Isfahani, A.; Moghadam, M.; Tangestaninejad, S.; Mirkhani, V.; Mohammadpoor-Baltork, I. Development of a novel bi-enzymatic silver dendritic hierarchical nanostructure cascade catalytic system for efficient conversion of starch into gluconic acid. Chem. Eng. J. 2019, 356, 423-435. [CrossRef]

43. Kouassi, G.K.; Irudayaraj, J.; Mccarty, G. Activity of glucose oxidase functionalized onto magnetic nanoparticles. Biomagn. Res. Technol. 2005, 3, 1. [CrossRef] [PubMed]

44. Abraham, R.E.; Verma, M.L.; Barrow, C.J.; Puri, M. Suitability of magnetic nanoparticle immobilised cellulases in enhancing enzymatic saccharification of pretreated hemp biomass. Biotechnol. Biofuels 2014, 7, 90. [CrossRef] [PubMed]

45. Wang, N.; Wu, R.; Fu, Q.; Wang, H.; Zhang, Z.; Haji, Z.; Li, X.; Lian, X.; An, Y. Immobilization of $\beta$-Glucosidase BglC on Decanedioic Acid-Modified Magnetic Nanoparticles. J. Chem. Eng. Technol. 2018, 41, 1949-1955. [CrossRef] 
46. Chouyyok, W.; Panpranot, J.; Thanachayanant, C.; Prichanont, S. Effects of $\mathrm{pH}$ and pore characters of mesoporous silicas on horseradish peroxidase immobilization. J. Mol. Catal. B Enzym. 2009, 56, $246-252$. [CrossRef]

47. Chapman, J.; Ismail, A.E.; Dinu, C.Z. Industrial Applications of Enzymes: Recent Advances, Techniques, and Outlooks. Catalysts 2018, 8, 238. [CrossRef]

48. Hsin Chi, H.; Radu, D.R.; Dezayas, G.; Penney, M.; Yu Lai, C. Stellate MSN-based Dual-enzyme Nano-Biocatalyst for the Cascade Conversion of Non-Food Feedstocks to Food Products. J. Thermodyn. Catal. 2017, 8, 2. [CrossRef]

49. Altun, S.; Çakıroğlu, B.; Özacar, M. A facile and effective immobilization of glucose oxidase on tannic acid modified $\mathrm{CoFe}_{2} \mathrm{O}_{4}$ magnetic nanoparticles. Colloids Surf. B Biointerfaces 2015, 136, 963-970. [CrossRef]

50. Chang, Q.; Tang, H. Immobilization of horseradish peroxidase on NH2-modified magnetic Fe3O4/SiO2 particles and its application in removal of 2,4-dichlorophenol. Molecules 2014, 19, 15768-15782. [CrossRef]

51. López-Gallego, F.; Guisán, J.M.; Betancor, L. Glutaraldehyde-mediated protein immobilization. Methods Mol. Biol. 2008, 1051, 33-41. [CrossRef]

52. Bradford, M.M. A rapid and sensitive method for the quantitation of microgram quantities of protein utilizing the principle of protein-dye binding. Anal. Biochem. 1976, 72, 248-254. [CrossRef]

53. Miller, G.L. Use of Dinitrosalicylic Acid Reagent for Determination of Reducing Sugar. Anal. Chem. 1959, 31, 426-428. [CrossRef]

54. Bowers, G.N.; Mccomb, R.B.; Christensen, R.C.; Schaffer, R. High-purity 4-nitrophenol: Purification, characterization, and specifications for use as a spectrophotometric reference material. Clin. Chem. 1980, 26, 724-729. [PubMed]

55. Scott, S.L.; Chen, W.; Bakac, A.; Espenson, J.H. Spectroscopic parameters, electrode potentials, acid ionization constants, and electron exchange rates of the 2,2' -azinobis(3-ethylbenzothiazoline-6-sulfonate)radicals and ions. J. Phys. Chem. 1993, 97, 6710-6714. [CrossRef]

(C) 2019 by the authors. Licensee MDPI, Basel, Switzerland. This article is an open access article distributed under the terms and conditions of the Creative Commons Attribution (CC BY) license (http://creativecommons.org/licenses/by/4.0/). 